\title{
NCA-LDAS Land Analysis: Development and Performance of a Multisensor, Multivariate Land Data Assimilation System for the National Climate Assessment $\mathscr{0}$
}

\author{
SUJAY V. KUMAR AND MiCHAEL JASINSKI \\ Hydrological Sciences Laboratory, NASA Goddard Space Flight Center, Greenbelt, Maryland \\ DAVID M. MOCKO \\ Science Applications International Corporation, Beltsville, and Global Modeling and Assimilation Office, and Hydrological Sciences \\ Laboratory, NASA Goddard Space Flight Center, Greenbelt, Maryland \\ MATTHEW RODELL \\ Hydrological Sciences Laboratory, NASA Goddard Space Flight Center, Greenbelt, Maryland \\ JORDAN BORAK, BAILING LI, AND HIROKO KATO BEAUDOING \\ Earth System Science Interdisciplinary Center, University of Maryland, College Park, College Park, and Hydrological Sciences Laboratory, \\ NASA Goddard Space Flight Center, Greenbelt, Maryland \\ CHRISTA D. PETERS-LIDARD \\ Hydrological Sciences Laboratory, NASA Goddard Space Flight Center, Greenbelt, Maryland
}

(Manuscript received 7 July 2017, in final form 5 February 2018)

\begin{abstract}
This article describes one of the first successful examples of multisensor, multivariate land data assimilation, encompassing a large suite of soil moisture, snow depth, snow cover, and irrigation intensity environmental data records (EDRs) from the Scanning Multichannel Microwave Radiometer (SMMR), Special Sensor Microwave Imager (SSM/I), Advanced Scatterometer (ASCAT), Moderate-Resolution Imaging Spectroradiometer (MODIS), Advanced Microwave Scanning Radiometer (AMSR-E and AMSR2), Soil Moisture Ocean Salinity (SMOS) mission, and Soil Moisture Active Passive (SMAP) mission. The analysis is performed using the NASA Land Information System (LIS) as an enabling tool for the U.S. National Climate Assessment (NCA). The performance of the NCA Land Data Assimilation System (NCA-LDAS) is evaluated by comparing it to a number of hydrological reference data products. Results indicate that multivariate assimilation provides systematic improvements in simulated soil moisture and snow depth, with marginal effects on the accuracy of simulated streamflow and evapotranspiration. An important conclusion is that across all evaluated variables, assimilation of data from increasingly more modern sensors (e.g., SMOS, SMAP, AMSR2, ASCAT) produces more skillful results than assimilation of data from older sensors (e.g., SMMR, SSM/I, AMSR-E). The evaluation also indicates the high skill of NCA-LDAS when compared with other LSM products. Further, drought indicators based on NCA-LDAS output suggest a trend of longer and more severe droughts over parts of the western United States during 1979-2015, particularly in the southwestern United States, consistent with the trends from the U.S. Drought Monitor, albeit for a shorter 2000-15 time period.
\end{abstract}

Supplemental information related to this paper is available at the Journals Online website: https://doi.org/10.1175/ JHM-D-17-0125.s1.

Corresponding author: Sujay Kumar, sujay.v.kumar@nasa.gov

\section{Introduction}

Land data assimilation systems (LDASs) are environments where land surface models (LSMs) are driven by observation-based meteorology in an offline (uncoupled to the atmosphere) manner to generate high-quality longterm and near-term estimates of land surface states and 
fluxes. There is a long legacy of such systems at global [Global Land Data Assimilation System (GLDAS; Rodell et al. 2004)], continental [North American Land Data Assimilation System (NLDAS; Mitchell et al. 2004; Xia et al. 2012a], and regional [Famine Early Warning Systems Network (FEWSNET) Land Data Assimilation System (FLDAS; McNally et al. 2017)] scales. These offline LDASs have enabled focused evaluation and improvement of land surface models and are often used to support a variety of end-use applications. The outputs of GLDAS, NLDAS, and FLDAS systems, for example, are routinely used for agricultural and water resources management, operational drought monitoring, and food security applications, among others.

A stated emphasis of the LDASs is the incorporation of observational constraints on the modeled estimates through data assimilation (DA) methods. Most LDAS environments to date, however, have only included a limited assimilation of terrestrial remote sensing measurements. Recent studies have focused on addressing this limitation through the assimilation of remotely sensed soil moisture (Reichle et al. 2007; Bolten et al. 2009; Q. Liu et al. 2011; Han et al. 2014; Kumar et al. 2014; Pipunic et al. 2014; Lievens et al. 2015; de Lannoy et al. 2015), snow depth (de Lannoy et al. 2012; Kumar et al. 2014; Dziubanski and Franz 2016), snow cover (Zaitchik and Rodell 2009; Fletcher et al. 2012; Zhang et al. 2014; Kumar et al. 2015), vegetation (Barbu et al. 2014; Fairbairn et al. 2017), and terrestrial water storage (Su et al. 2010; Houborg et al. 2012; Li et al. 2012; Tangdamrongsub et al. 2015; Girotto et al. 2016; Kumar et al. 2016) retrievals within LDAS configurations. Many of these LDAS configurations have been implemented using the NASA Land Information System (LIS; Kumar et al. 2006; Peters-Lidard et al. 2007; Kumar et al. 2008) software, which includes a comprehensive set of tools for enabling concurrent instances of multisensor, multivariate land data assimilation. This article describes the development of a continental scale LDAS using LIS in the NLDAS configuration, known as the National Climate Assessment (NCA) LDAS (NCA-LDAS). The primary goal of NCA-LDAS is to develop an integrated water analysis through the assimilation of multiple remote sensing measurements of the terrestrial water cycle.

The NCA is an interagency effort of the U.S. Global Change Research Program (USGCRP) to understand the impact of changing climate in order to support decision-making across the United States. The key objectives of NCA include the development of information about the current status and anticipated trends of the climate through the integration of information from available observational and modeling platforms. The NCA effort focuses on evaluating the impact of climate change in several sectors, including human health, energy, agriculture, and water, among others. Recently, a set of indicators was developed (Kenney et al. 2016), with the primary goal of supporting the sustained U.S. NCA (Buizer et al. 2016) by providing long-term information that is regularly updated about key U.S. impacts on systems and sectors, such as water cycle and water management (required by the 1990 Global Change Research Act or of broad concern to the U.S. public). The NCA-LDAS has been developed as an end-to-end enabling tool for the water sector of the NCA to develop an integrated water analysis by leveraging the terrestrial modeling, remote sensing, and data assimilation capabilities of the NASA LIS. The NCA-LDAS leverages the advancements made through univariate data assimilation studies to enable a unique, first-of-its-kind land surface reanalysis over the continental United States (CONUS) for the past 30+ years.

Reanalysis methods help to generate comprehensive climatic data products over an extended time period by combining available observations and numerical model estimates through consistent assimilation schemes. The development of such products has been invaluable for climate monitoring and research. Most reanalysis efforts (Kalnay et al. 1996; Uppala et al. 2005; Onogi et al. 2005; Saha et al. 2010; Rienecker et al. 2011; Bosilovich et al. 2017), however, are focused on atmospheric analysis where the observations are assimilated into an atmospheric general circulation model. The need to extend such analysis to reflect observations of other Earth system components of ocean, sea ice, and land has been well established (Trenberth et al. 2008). Though derived land surface components of the reanalysis that employ the forcings from the atmospheric reanalysis products have been developed (Reichle et al. 2011; Balsamo et al. 2015; Reichle et al. 2017), these products often do not include the direct assimilation of land remote sensing data products. The NCA-LDAS, on the other hand, uses a large suite of land remote sensing retrieval products to produce a one-of-a-kind multivariate, multisensor land reanalysis for the CONUS spanning 36 years from 1979 to 2015.

NCA-LDAS has been developed by leveraging the advancements made in the development of LDASs that integrate land surface model and hydrological observations. Specifically, NCA-LDAS consolidates the capabilities of the NASA LIS software to assimilate water availability environmental data records (EDRs) from remote sensing platforms from 1979 to 2015 over North America, using the Noah land surface model. The analysis employs soil moisture products from a number of 
microwave instruments, including the Scanning Multichannel Microwave Radiometer (SMMR; 1978-87), the Special Sensor Microwave Imager (SSM/I; since 1987), the Advanced Microwave Scanning Radiometer for Earth Observing System (AMSR-E; 2002-11), the Advanced Scatterometer (ASCAT; 2007-15), the Soil Moisture and Ocean Salinity (SMOS; 2012-15) mission, and NASA's Soil Moisture Active Passive (SMAP; 2015 onward) mission. Similarly, snow depth retrievals from a number of passive microwave instruments including SMMR, SSM/I, AMSR-E, and Advanced Microwave Scanning Radiometer 2 (AMSR2; 2012-15) are employed in the reanalysis. In addition, snow cover products from the Interactive Multisensor Snow and Ice Mapping System (IMS; 1998-2015) and Moderate Resolution Imaging Spectroradiometer (MODIS; 2000-2015) aboard the NASA Aqua satellite are employed in NCA-LDAS. MODIS retrievals rely on visible spectrum retrievals whereas IMS data are a blend of visible data from geostationary and polar-orbiting satellites and passive microwave data. Finally, NCA-LDAS also include formulations of irrigation simulation using the irrigated area records derived from MODIS with an image classification algorithm.

The primary objective of this article is to document the performance of NCA-LDAS in terms of its utility to develop an improved characterization of the continental-scale water budget. The impact of assimilating the abovementioned remote sensing retrievals on the terrestrial water states and fluxes is quantified by a comparison to a large suite of available reference data. The article also presents a comparison of the performance of the NCA-LDAS relative to outputs from other LDASs and land analysis efforts. In addition to quantifying the value of terrestrial remote sensing data for improving the mean estimates of fluxes and states, the article also examines the utility of NCA-LDAS for representing hydrological extremes and climate-relevant water availability applications such as drought monitoring. This article builds on prior univariate studies (Kumar et al. 2014, 2016) that have quantified the positive impacts from land data assimilation for drought monitoring and examines the trends of the hydrologic indicators that encapsulate the dry extremes of the water budget.

The paper is organized as follows. Section 2 provides a brief description of the model configuration, data sources, and details about the assimilation setup. Section 3 presents the evaluation of key water budget components from NCA-LDAS, and section 4 examines the utility of NCA-LDAS-based drought indicators. Finally, section 5 provides the summary and main conclusions.

\section{Approach}

\section{a. Model configuration}

The NCA-LDAS uses a model domain configuration similar to the one used in the NLDAS project. The model simulations are conducted on an equidistant cylindrical grid spanning the CONUS $\left(25-53^{\circ} \mathrm{N}\right.$ and $\left.125-67^{\circ} \mathrm{W}\right)$ at $1 / 8^{\circ}$ spatial resolution. All model integrations are forced with the NLDAS phase 2 (NLDAS-2) meteorology (Xia et al. 2012a), which is primarily derived from the North American Regional Reanalysis (NARR; Mesinger et al. 2006). The satellite derived radiation products (Pinker et al. 2003) are used to bias correct the downward shortwave radiation fields. The NLDAS-2 precipitation is generated by temporally disaggregating the daily NOAA Climate Prediction Center's (CPC) unified daily gauge analysis of precipitation to hourly time scales. The temporal disaggregation is performed (primarily) using the NCEP Stage II Doppler radar data (Baldwin and Mitchell 1997). The NLDAS-2 precipitation also includes orographic adjustments based on the ParameterElevation Regressions on Independent Slopes Model (PRISM; Daly et al. 1994).

The Noah LSM (version 3.3; Ek et al. 2003) implemented within the NASA LIS is used in the NCALDAS simulations. The simulations are conducted with a 15-min time step during the time period from 1 January 1979 to 1 January 2016. The LSM is initialized with uniform conditions and run from 1979 to 2015 twice. A climatological initial condition is generated from this model spinup to initialize the NCA-LDAS runs beginning on 1 January 1979. The streamflow estimates are generated using the Hydrological Modeling and Analysis Platform (HyMAP; Getirana et al. 2012) model. The gridded surface runoff and baseflow fields from the LSM are used by HyMAP to derive streamflow estimates. HyMAP also models the interaction between rivers and floodplains, floodplain water flow among grid cells, and evaporation from open water. HyMAP is configured within NCA-LDAS to run at the same spatial and temporal resolutions and extents as that of the Noah LSM.

\section{b. Satellite retrievals}

Figure 1 shows a chronological schematic of all the retrievals employed for data assimilation within NCA-LDAS. They include four categories of satellite EDRs: 1) soil moisture, 2) snow depth, 3) snow cover, and 4) irrigation intensity. Soil moisture retrievals from six satellite microwave instruments exploiting the sensitivity to soil moisture in the low-frequency microwave range are used in the NCA-LDAS. Soil moisture retrievals (based 


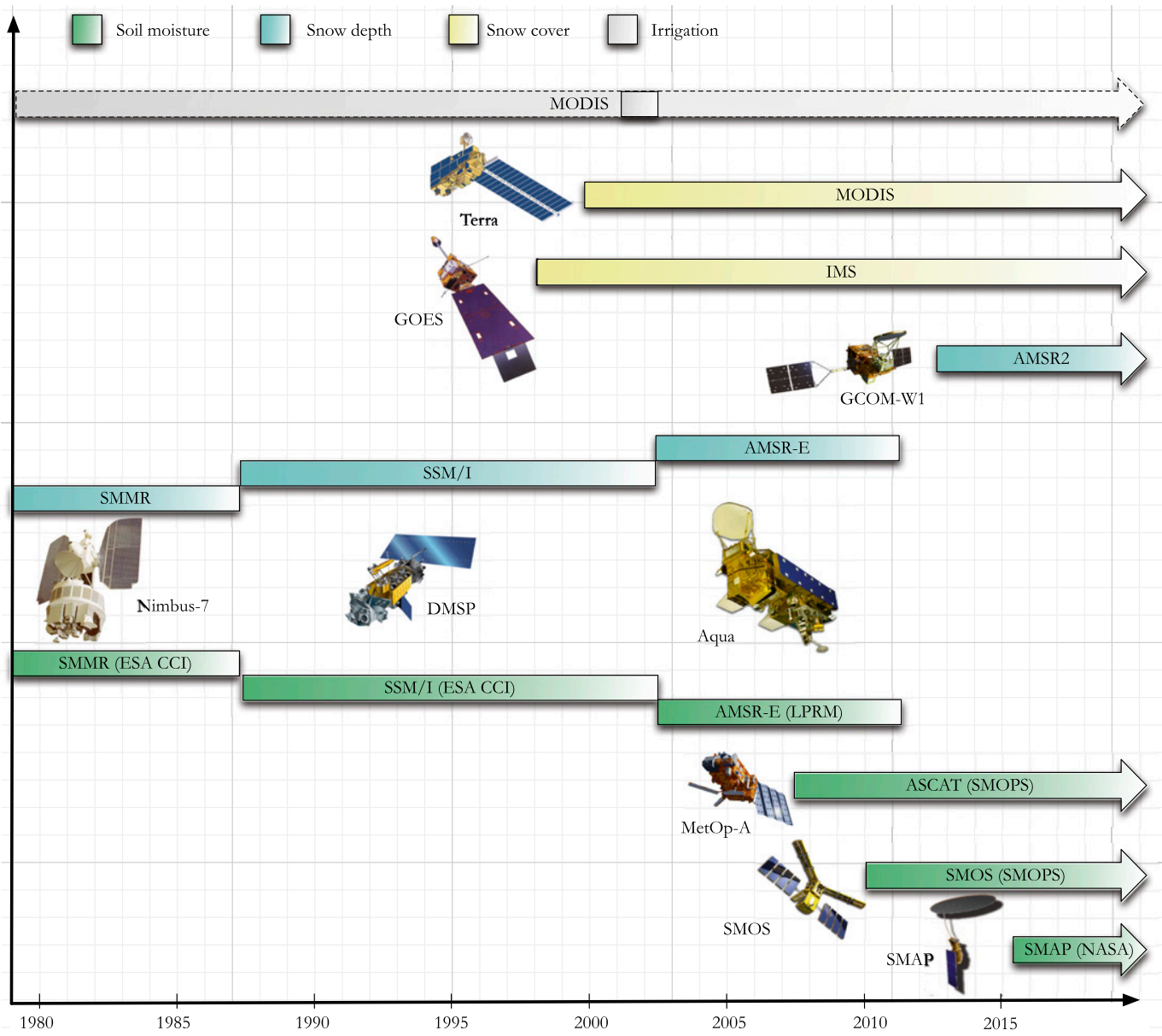

FIG. 1. Chronological schematic of the satellite remote sensing retrievals and the satellite sources used in NCALDAS. The dashed lines for irrigation represent the fact that irrigation is applied throughout the NCA-LDAS time period, though the irrigation intensity map from MODIS was derived for the single year of 2001 (shown as a solid box).

on $\mathrm{C}$ and $\mathrm{X}$ bands) from the SMMR instrument aboard the Nimbus-7 satellite are used from 1979 to 1987. From 1987 to 2002, retrievals from SSM/I instrument (based on $\mathrm{Ku}$ band) aboard the Defense Meteorological Satellite Program (DMSP) satellites are used, whereas retrievals from AMSR-E (based on C and X bands) on the NASA Aqua satellite are used from 2002 to 2011. From 2007 onward, retrievals from multiple platforms are used concurrently, with ASCAT (aboard the MetOp-A satellite) retrievals (based on C-band backscatter) from 2007, SMOS retrievals from 2010, and SMAP retrievals from 2015 onward. SMOS and SMAP are dedicated soil moisture missions relying on L-band $(1.4 \mathrm{GHz})$ passive microwave measurements. The retrievals from each of these instruments are obtained through different retrieval algorithms and systems. The multisensor, blended soil moisture product developed by the European Space
Agency (ESA) [known as the ESA Climate Change Initiative (CCI) data; Y. Liu et al. 2011; Dorigo et al. 2017] is used to include the retrievals from SMMR and SSM/I during the time period of 1979-2002. The AMSR-E retrievals are generated using the Land Parameter Retrieval Model (LPRM; Owe et al. 2008). The Soil Moisture Operational Products System (SMOPS; Liu et al. 2012) of NOAA/NESDIS is used to obtain the backscatter measurements acquired by the C-band active microwave measurements of ASCAT as well as the L-band radiometer measurements of SMOS. The level 3 SMAP retrieval products (L3_SM_P; O'Neill et al. 2015) available through the National Snow and Ice Data Center (NSIDC) are also used in the DA integrations.

A similar suite of passive microwave radiometrybased snow depth retrievals are used for assimilation within NCA-LDAS. From 1979 to 1987, retrievals from 
SMMR using the 19- and 37-GHz channels (Chang et al. 1987) are used. A similar set of retrievals from SSM/I are assimilated from 1987 to 2002. The AMSR-E retrievals (Kelly 2009; Kelly et al. 2003), exploiting measurements from several channels $(10,18,23,36$, and $89 \mathrm{GHz})$, are employed during the time period from 2002 to 2011. Finally, the AMSR2 retrievals (Oki et al. 2010; Kachi et al. 2013) are employed for assimilation from July 2012 onward. As AMSR-E stopped functioning in October 2011 , there is a period of 8 months with no snow depth retrievals during 2011-12. Based on the strategy developed by Kumar et al. (2015), visible-spectrum-based snow cover area (SCA) measurements are used in NCA-LDAS to provide snow detection constraints during the assimilation of snow depth retrievals. Two different sources of SCA observations are employed: 1 ) the NOAA IMS (Ramsay 1998), which is a blend of visible data from geostationary and polar-orbiting satellites and passive microwave data, and 2) MODIS Terra SCA retrievals (MOD10C1; Hall and Riggs 2016). The IMS and MODIS data are used from 1998 and 2000 onward, respectively. Passive microwave snow depth retrievals are assimilated only if both IMS and MODIS data indicate valid, nonzero snow cover.

To include representations of human-managed agricultural landscapes, NCA-LDAS uses a demand-driven, sprinkler irrigation scheme (Ozdogan et al. 2010). A 1-km irrigation gridcell fraction map, derived by merging gridded climate datasets and MODIS data through an image classification algorithm (Ozdogan and Gutman 2008), is used to provide representations of irrigated areas over the CONUS. In the sprinkler irrigation scheme, irrigation is triggered when the root-zone soil moisture falls below the transpiration stress threshold for a given grid cell. The irrigation requirement is computed as an equivalent height of water and is included as part of the precipitation input to the LSM. The irrigation scheme is only applied over cropland and grassland vegetation types and is only enabled during the growing season, daily between 0600 and 1000 local time. Though the MODIS-based irrigation intensity map was derived for a single year (2001), we use it throughout the NCA-LDAS time period of 1979-2015 to represent irrigated areas over the CONUS.

\section{c. Data assimilation method}

Similar to previous univariate data assimilation studies in the NLDAS configuration (Kumar et al. 2014, 2015), the NCA-LDAS employs a one-dimensional ensemble Kalman filter (EnKF; Reichle et al. 2002) for the concurrent assimilation of satellite EDRs into the Noah LSM. Various satellite EDRs are assimilated in a sequential manner, where the ensemble of model forecasts are propagated forward in time by the LSM followed by the analysis step that updates them based on observations. When multiple satellite EDRs are available, they are incorporated based on their respective measurement or overpass times. The general form of the analysis step can be written as

$$
\mathbf{x}_{k}^{+}=\mathbf{x}_{k}^{-}+\mathbf{K}_{k}\left(\mathbf{y}_{k}-\mathbf{H}_{k} \mathbf{x}_{k}^{-}\right),
$$

where $\mathbf{x}^{-}$is the model state vector prior to the update, $\mathbf{x}^{+}$is the posterior state vector, $\mathbf{y}_{k}$ is the observation vector, and $\mathbf{H}_{k}$ is the observation operator that relates the model states to the observations. The subscript $k$ indicates time, and the superscripts - and + refer to the state estimates, before and after the update, respectively. Matrix $\mathbf{K}_{k}$ is the gain matrix, which represents the weighting factor that determines the degree to which the model forecast is adjusted toward the observation.

The term $\left(\mathbf{y}_{k}-\mathbf{H}_{k} \mathbf{x}_{k}^{-}\right)$represents the innovation vector, which is the difference between the observations and the model's prediction of the observations. The representation of $\mathbf{y}_{k}$ and $\mathbf{H}_{k}$ must be done carefully to ensure consistency with respect to a number of factors: 1) both $\mathbf{y}_{k}$ and $\mathbf{H}_{k}$ terms should be specified in the same physical space, with the observations and the model forecasts collocated on the same geographical space, and 2) observations and model forecasts should be unbiased relative to each other, as DA systems are designed to work primarily with unbiased errors (Dee and da Silva 1998). In most prior DA studies, observations were spatially interpolated to the model resolution to address the spatial-resolution mismatches. In NCA-LDAS, we follow a different strategy by upscaling or interpolating the $\mathbf{H}_{k}$ term to match the resolution of the observations. If the observations are at a coarser resolution than $1 / 8^{\circ}$, the $\mathbf{H}_{k}$ term is upscaled through simple averaging to match the observation EDR space. On the other hand, if the observations are at a finer resolution than $1 / 8^{\circ}$, the $\mathbf{H}_{k}$ term is spatially interpolated to the observation resolution.

Consistent with prior univariate studies (Reichle et al. 2007, 2010; Q. Liu et al. 2011; Kumar et al. 2012b, 2014) to address the bias issues in the DA configurations, NCA-LDAS employs a number of strategies so that the observations $\mathbf{y}_{k}$ and the model forecasts $\mathbf{H}_{k}$ are generally unbiased relative to each other. For soil moisture DA, the observations are rescaled to the model climatology using cumulative density function (CDF) matching (Reichle and Koster 2004). The CDF matching is performed separately for each satellite soil moisture EDR, where the observation CDFs are computed separately for each EDR in their respective geographical grid. 
Similarly, the model CDFs are also computed separately at each EDR observation grid. The CDF computations use the entire available archive of each data record. The input observation error standard deviations for the unscaled soil moisture retrievals are set to $0.05,0.08,0.08$, 0.04, and $0.04 \mathrm{~m}^{3} \mathrm{~m}^{-3}$ for ESA CCI, AMSR-E, ASCAT, SMOS, and SMAP, respectively. These settings are based on a combination of values from prior studies (Q. Liu et al. 2011; Kumar et al. 2014), a comparison of the dynamic range of these products, and the reported error levels of retrievals. Spatially distributed observation error standard deviations are generated by scaling these input error standard deviations by the ratio of the soil moisture time series standard deviation of the Noah LSM to that of the soil moisture retrievals (Q. Liu et al. 2011; Kumar et al. 2014). The scaled observation error standard deviations are generally comparable across different sensors, with the domain-averaged error roughly between 0.03 and $0.05 \mathrm{~m}^{3} \mathrm{~m}^{-3}$ (shown in Fig. S1 in the online supplementary material). The snow depth EDRs are bias corrected using available in situ measurements of the Global Historical Climate Network (GHCN; Menne et al. 2012) using the Cressman objective analysis (Cressman 1959). The bias correction is conducted separately for SMMR, SSM/I, AMSR-E, and AMSR2 snow depth EDRs. The objective analysis updates the satellite EDRs by weighting the residuals between the station and satellite EDRs at each grid point. The weighting functions are based on the differences in horizontal and vertical distances between the station location and the model grid point, as described in Kumar et al. (2014). The observation error standard deviation is assumed to be $50 \mathrm{~mm}$ for all bias-corrected snow depth retrievals. Studies such as de Rosnay et al. (2014) have documented that Cressman analysis could lead to spurious patterns in the snow analysis, particularly when the density of stations used in the analysis is small. Such artifacts were not observed in the current analysis, likely because of the sufficient spatial density of the GHCN stations (Kumar et al. 2014). As future NCA-LDAS configurations employ model configurations at finer spatial resolutions, the snow analysis will be improved by the use of methods such as optimal interpolation (OI).

Note that the soil moisture DA configuration essentially incorporates the anomaly information whereas snow DA assimilates the direct geophysical quantities. Direct assimilation for soil moisture is difficult because of the significant differences in the model estimates and satellite retrievals in their geophysical definitions and spatial (both horizontal and vertical) representativeness. The model soil moisture is essentially an index of wetness (Koster et al. 2009) and is generally inconsistent with the satellite soil moisture retrievals. As a result, direct assimilation of soil moisture retrievals is meaningless, unless explicit care is done to resolve their relative inconsistencies. De Lannoy et al. (2012) examined the use of both anomaly and direct assimilation strategies for snow DA and found that direct assimilation is more effective in improving snow states through DA. Therefore, we employ anomaly assimilation for soil moisture DA and direct assimilation for snow depth DA.

The DA simulations use an ensemble size of 20 with perturbations applied to meteorological fields and model prognostic fields to maintain ensemble spreads representing the uncertainty in model estimates. The precipitation $P$ and downward shortwave radiation (SW) meteorological fields are perturbed, with multiplicative perturbations with a mean of 1 and standard deviations of 0.3 and 0.5 , respectively. In addition, additive perturbations with a standard deviation of $50 \mathrm{~W} \mathrm{~m}^{-2}$ are applied to the longwave $(\mathrm{LW})$ radiation fields. For soil moisture DA, the model state vector consists of the total soil moisture prognostic variables for each of the four soil layers $\left(\mathrm{SM}_{i}, i=1, \ldots, 4\right)$. The surface soil moisture layer is perturbed with an additive noise of $0.001 \mathrm{~m}^{3} \mathrm{~m}^{-3}$. Similarly, for snow DA, the model fields of snow water equivalent (SWE) and snow depth (SD) are perturbed with multiplicative noise of 0.005 and 0.01 , respectively. Time series correlations are employed through a first-order regressive model [AR(1)] with time scales of 24 and $12 \mathrm{~h}$ for the forcing variables and model fields, respectively. The forcing fields are perturbed hourly, whereas the model fields are perturbed every $3 \mathrm{~h}$. To enable a realistic balance in the perturbations of related variables (Reichle et al. 2007), cross correlations $\rho$ to perturbations between state variables $\left[\rho(\mathrm{SWE}, \mathrm{SD})=0.9, \rho\left(\mathrm{SM}_{1}, \mathrm{SM}_{2}\right)=0.6\right.$, $\left.\rho\left(\mathrm{SM}_{1}, \mathrm{SM}_{3}\right)=0.4, \rho\left(\mathrm{SM}_{1}, \mathrm{SM}_{4}\right)=0.2\right]$ and forcing fields $[\rho(\mathrm{SW}, P)=-0.8, \rho(\mathrm{SW}, \mathrm{LW})=-0.5, \rho(\mathrm{LW}, P)=0.5]$ are also imposed, based on Kumar et al. (2014).

A number of observation thinning procedures are also employed in the DA configurations to account for the sensing limitations of the remote sensing measurements. The soil moisture retrievals are excluded for being at the edge of the swath or near water bodies and when impacted by dense vegetation, precipitation, frozen ground, snow cover, or radio frequency interference (RFI) based on the information provided in the EDRs. Both active and passive microwave retrievals are susceptible to contamination from manmade RFI (Njoku et al. 2003; Soldo et al. 2016; Ticconi et al. 2017). In addition, the soil moisture observations are screened out when the LSM indicated active precipitation, nonzero snow cover, frozen soil, or dense 
vegetation. Similarly, the snow depth retrievals are excluded over dense vegetation and when the model skin temperature or the top layer soil temperature is higher than $5^{\circ} \mathrm{C}$. Finally, the snow cover observations from MODIS are considered valid if the associated cloud cover is less than $10 \%$ and the observation of snow cover fraction is greater than $25 \%$. These observation thinning strategies are based on the approaches developed in prior univariate studies (Kumar et al. 2014, 2015). Figure 2 shows the total number of soil moisture, snow depth, and snow cover observations ingested each year in NCA-LDAS after the observation thinning procedures. The number of assimilated soil moisture observations increases gradually from 1979 to 2015, as the quality and availability of soil moisture retrievals increase. The number of assimilated snow depth observations also increases from the SMMR (1979-1987) to the SSM/I (1987-2002) time period. During the 1998-2011 time period, there is a marginal reduction in the number of assimilated snow depth observations due to the added constraint of snow cover observations. The large decrease in the number of snow depth observations in years 2011 and 2012 is due to the loss of AMSR-E in late 2011 and because the AMSR2 data became available only in August 2012. The increase in the snow cover observations from the year 2000 onward are due to the added use of MODIS data starting in 2000 .

\section{Evaluation of the NCA-LDAS analysis}

The primary goal of NCA-LDAS is to produce an integrated terrestrial water analysis for the CONUS informed by remote sensing observations. In this section, a comprehensive evaluation of the key terrestrial water budget components of soil moisture, snow depth, streamflow, and evapotranspiration (ET) is presented through comparison against a large suite of available reference data products. For each variable, the impact of data assimilation is evaluated by comparing the performance improvement relative to the ensemble open-loop (OL) integration that does not include any data assimilation, but includes the perturbations to meteorological and model state variables. The overall quality of the NCA-LDAS estimates is also evaluated by a comparison with eight other land analysis products. The evaluation is conducted using the NASA Land Surface Verification Toolkit (LVT; Kumar et al. 2012a), which is a formal land surface verification and benchmarking environment.

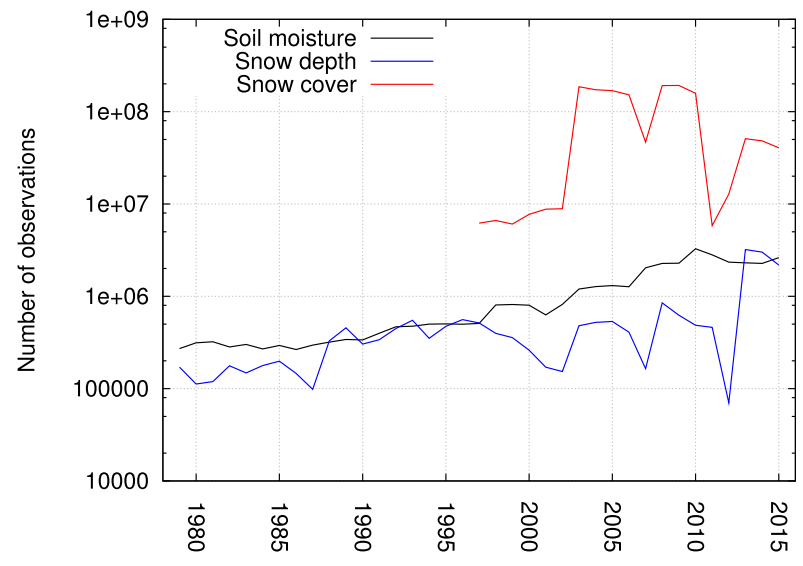

FIG. 2. Annual number of soil moisture, snow depth, and snow cover measurements (aggregated from daily observations across the modeling domain) employed for analysis within NCA-LDAS.

\section{a. Soil moisture evaluation}

The NCA-LDAS soil moisture estimates are evaluated using three different in situ soil moisture network data: 1) USDA Agricultural Research Service (ARS) experimental watersheds (Jackson et al. 2010), 2) the USDA Soil Climate Analysis Network (SCAN; Schaefer et al. 2007), and 3) the NOAA U.S. Climate Reference Network (USCRN; Diamond et al. 2013; Bell et al. 2013). The USDA ARS experimental watersheds provide surface soil moisture measurements at seven locations in the CONUS, whereas the SCAN and USCRN networks provide hourly soil profile measurements at depths of 5,10,20,50, and $100 \mathrm{~cm}$ wherever possible. After careful quality control, the details of which are described in Q. Liu et al. (2011), data from 123 SCAN stations and 86 USCRN stations are employed in the evaluations. As the measurements tend to be sparse in the deeper layers (particularly at 50 -and $100-\mathrm{cm}$ depths), we use a depth-weighted average of the first three layers $(5,10$, and $20 \mathrm{~cm})$ as the observed root-zone soil moisture. This approach is consistent with the strategy used in the prior studies (Q. Liu et al. 2011; Kumar et al. 2014). The USDA ARS data are available from 2001, SCAN from 2000, and USCRN from 2011 onward. Similar to prior studies, the anomaly correlation $R$ metric is used as the metric for evaluating NCA-LDAS soil moisture estimates, as climatology differences between model and in situ observations make a direct comparison difficult (Koster et al. 2009). At each grid point, the anomaly values are computed by subtracting the monthly mean soil moisture values from the daily averages, for in situ observations and the model. The anomaly $R$ values are then computed as the 

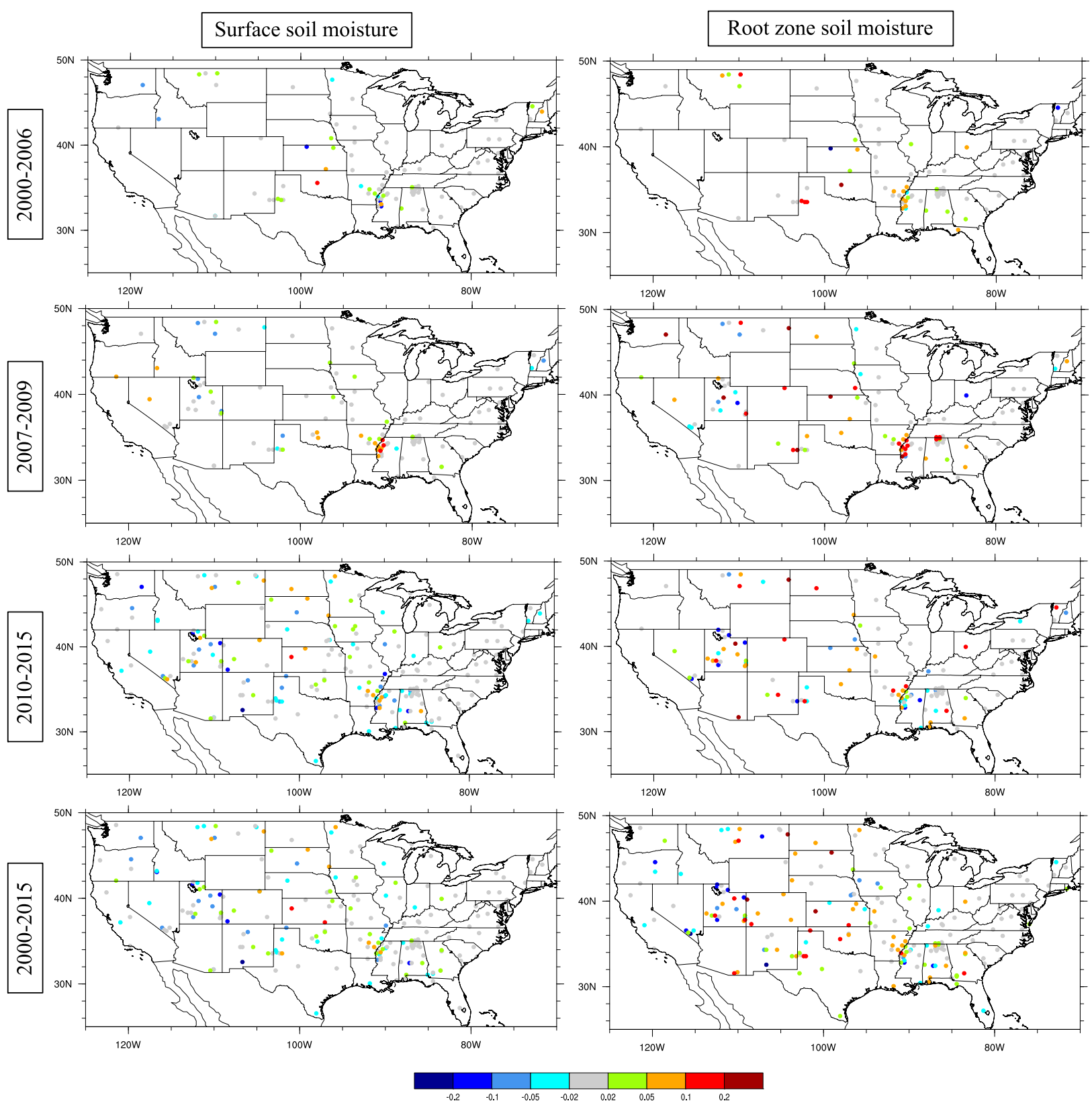

FIG. 3. Comparison of the anomaly $R$ improvements in (left) surface and (right) root-zone soil moisture, relative to USDA ARS, NRCS SCAN, and USCRN station network data. (bottom) The improvement maps for the entire evaluation time period. The evaluation stratified by three time periods: (top) 2000-06, (second row) 2007-09, and (third row) 2010-15. The warm and cool colors indicate improvements and degradations from DA, respectively.

correlation of the daily anomalies from the two data sources.

Figure 3 shows anomaly $R$ "improvement maps" for surface and root-zone soil moisture (anomaly $R$ from NCA-LDAS minus the anomaly $R$ from the OL), where warm colors indicate locations where NCA-LDAS estimates are improved relative to the OL. The root-zone soil moisture values are computed as a weighted average of soil moisture values in the top $1 \mathrm{~m}$ of soil. The bottom row of Fig. 3 shows the comparison of the anomaly $R$ values for the entire simulation period (2000-15) where ground reference datasets are available. The domain-averaged anomaly $R$ values for surface and root-zone soil moisture from the OL are 0.57 and 0.55 , respectively. The multivariate assimilation provides a marginal, domain-averaged improvement in 
NCA-LDAS, where the domain-averaged anomaly $R$ values are 0.58 and 0.59 for surface and root-zone soil moisture, respectively. For surface soil moisture, there are more significant regional improvements over the Great Plains and the Arkansas-Red and lower Mississippi basins; little impact over the Northeast, Southeast, and West Coast; and degradations over the Southwest (especially over Utah). Similar trends are also seen in the root-zone soil moisture comparison, with significant improvements over most locations except over the Southwest. In addition to anomaly $R$, the unbiased RMSE (ubRMSE; Entekhabi et al. 2010) estimates are also computed to evaluate the impact of DA on soil moisture states. The improvements (reductions) in the domain-averaged ubRMSE for surface and rootzone soil moisture are 0.03 and $0.01 \mathrm{~m}^{3} \mathrm{~m}^{-3}$, which are barely statistically significant. Larger differences similar to the spatial patterns of improvements and degradations of Fig. 3 were observed for ubRMSE (not shown).

To quantify the impact of assimilating EDRs from different sensors, the anomaly $R$ comparisons are stratified into three time periods. Years 2000-06 represent the assimilation of SSM/I and AMSR-E, 2007-09 represent the impact of AMSR-E and ASCAT, and 2010-15 primarily represent the impact of ASCAT, SMOS, and SMAP. Though the density of in situ stations vary during these time periods, the stratification of the improvements in Fig. 3 is helpful in assessing the added impact of data from newer sensors. Generally the regions with patterns of improvements and degradations are consistent in these temporal stratifications. Larger improvements over the high plains and Missouri River basin can be observed with the use of modern sensors, whereas the skills are comparable over the lower Mississippi and Arkansas-Red River basins.

\section{b. Snow depth evaluation}

Snow depth estimates from the NCA-LDAS are evaluated by comparing them to the spatially distributed snow depth estimates from the Canadian Meteorological Centre (CMC) daily snow depth analysis (Brown and Brasnett 2010; available daily from 1998 at approximately $25-\mathrm{km}$ spatial resolution) and the NOAA National Weather Service's National Operational Hydrologic Remote Sensing Center (NOHRSC) Snow Data Assimilation System (SNODAS; Barrett 2003; available daily from 2003 at 1-km spatial resolution). Both these data products are generated by combining ground-based, airborne, meteorological aviation reports, World Meteorological Organization (WMO) special aviation reports, and satellite-derived observations with estimates from a snow model. Since the available ground measurements of snow depth from
GHCN are already used in the bias correction of snow depth EDRs, we rely on the use of CMC and SNODAS, which are also modeled analysis products.

A comparison of the improvements in snow depth RMSE of NCA-LDAS estimates relative to CMC and SNODAS is shown in the bottom row of Fig. 4. The RMSE difference map is computed as the RMSE of the OL integration minus the RMSE of the NCA-LDAS simulation, so that positive differences indicate improvements and negative differences indicate degradations caused by DA. Overall, the patterns in Fig. 4 indicate that the NCA-LDAS estimates are improved relative to the OL estimates in both comparisons. Though the domain-averaged improvements in RMSE are small (2.3 and $6.2 \mathrm{~mm}$ relative to CMC and SNODAS, respectively), larger regional improvements are seen in Fig. 4. There are significant improvements in the midwestern United States, parts of the Rocky Mountains, and the northeastern United States. Areas of degradation, especially in the CMC comparison, are also seen in the region near the Great Lakes and parts of the western United States. These results are consistent with the univariate studies (Kumar et al. 2014), validating the DA strategy to employ bias-corrected snow depth EDRs.

Figure 4 also shows the evaluation of the NCA-LDAS snow depth estimates stratified into three time periods, 1998-2002, 2003-12, and 2013-15, associated with the assimilation of SSM/I, AMSR-E, and AMSR2 snow depth EDRs. The improvement map (compared to CMC) for the 1998-2002 time period indicates that only marginal improvements are obtained with the use of SSM/I snow depth EDRs. Comparatively, larger improvements (and smaller degradations) are seen with the use of AMSR-E and AMSR2. For example, over the U.S. Midwest, high plains, and Northeast, the NCALDAS shows significant improvements during the AMSR-E and AMSR2 time periods, whereas the assimilation of SSM/I frequently leads to less skillful snow depth estimates over these regions. Similar patterns are also seen in the SNODAS evaluations. The assimilation of AMSR2 provides stronger enhancements in snow depth relative to the improvements obtained with AMSR-E. These results indicate that the use of more modern snow depth sensors provide increased utility in data assimilation.

Note that, generally, the time periods of soil moisture and snow DA are mutually exclusive. It is, however, difficult to attribute the improvements in snow states solely to snow DA, as improvements in soil moisture characterization at the beginning of the snow season could impact the snow evolution and assimilation. In addition, there are time periods during both fall and 

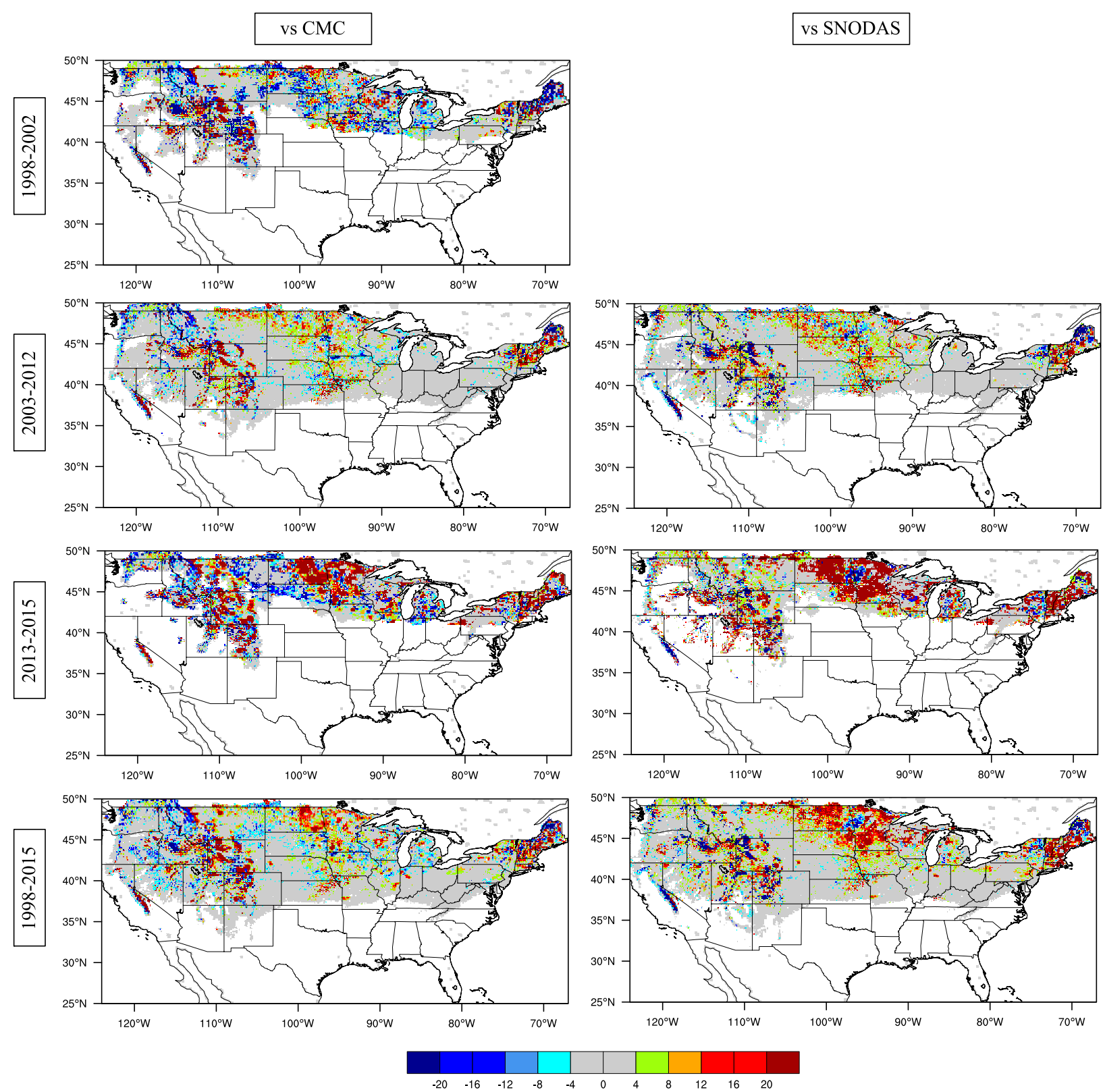

FIG. 4. Comparison of the improvements in snow depth RMSE (mm) using (left) CMC and (right) SNODAS as the reference data. (bottom) The RMSE improvement maps for the entire evaluation time period. The evaluation stratified by three time periods: (top) 19982002, (second row) 2003-12, and (third row) 2013-15, which represent the SSM/I, AMSR-E, and AMSR2 assimilation time periods, respectively. The warm and cool colors indicate improvements and degradations from DA, respectively.

spring where soil moisture and snow observations are simultaneously assimilated. Conversely, the changes to the moisture states from snow DA could also impact the soil moisture states, especially during the transition time periods (spring and fall).

\section{c. Streamflow evaluation}

The streamflow estimates from NCA-LDAS are evaluated by comparing them to daily streamflow data from the U.S. Geological Survey (USGS; http://nwis. waterdata.usgs.gov/nwis) over 572 small unregulated basins during the 1979-2015 time period. This subset of basins is selected for model evaluation as they have no visible signs of reservoir operations and are larger in size than the typical footprint of the passive microwave sensors (Xia et al. 2012b; Kumar et al. 2014).

Improvement maps of the NCA-LDAS streamflow estimates are shown in Fig. 5. The streamflow improvement 

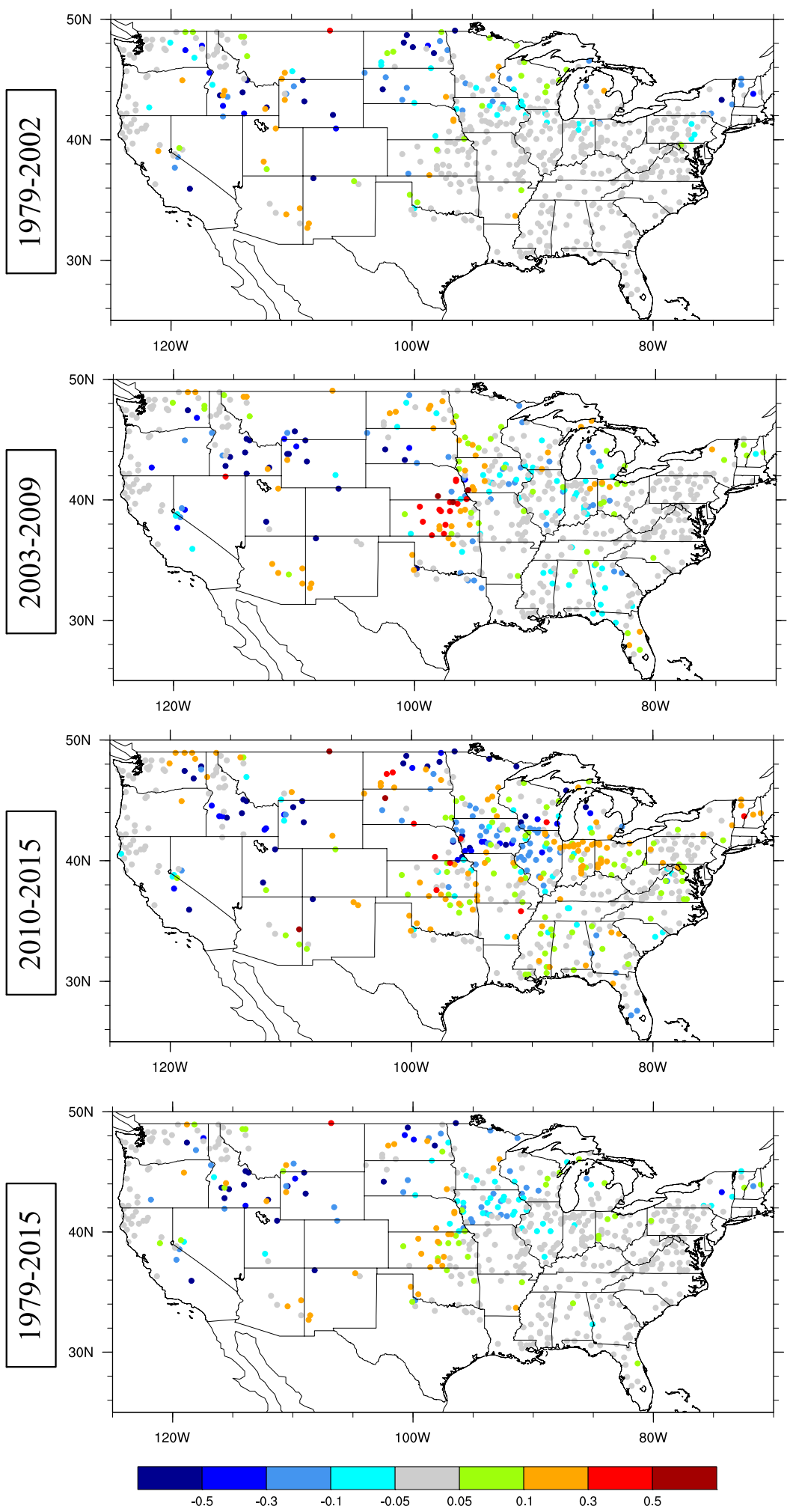

FIG. 5. Comparison of the improvements in streamflow NSE (as NSE NIC) using the USGS daily streamflow observations as the reference. (bottom) The improvement maps for the entire evaluation time period. The evaluation stratified by three time periods: (top) 1979-2002, (second row) 2003-09, and (third row) 2010-15. Positive values represent improvements from DA and negative values indicate degradations from DA. 
maps are computed as follows: First, Nash-Sutcliffe efficiency (NSE) values are computed for the OL and NCA-LDAS simulations by comparing the streamflow estimates from these integrations to USGS gauge measurements. A normalized information contribution (NIC; Kumar et al. 2009) measure is then computed to quantify the improvement or degradation due to data assimilation. The NSE NIC values are computed as

$$
\mathrm{NIC}_{\mathrm{NSE}}=\frac{\left(\mathrm{NSE}_{a}-\mathrm{NSE}_{o}\right)}{\left(1-\mathrm{NSE}_{o}\right)},
$$

where the subscripts $o$ and $a$ denote OL and analysis, respectively. The NIC metric provides a normalized measure of the improvement through data assimilation $\left(\mathrm{NSE}_{a}-\mathrm{NSE}_{o}\right)$ as a fraction of the maximum possible skill improvement $\left(1-\mathrm{NSE}_{o}\right)$. Thus, positive and negative NIC values indicate improvements and degradations in NCA-LDAS relative to OL streamflow estimates, respectively.

The bottom panel of Fig. 5 shows the NIC values computed for the entire NCA-LDAS time period of 1979-2015. Overall, the impact of assimilation on streamflow estimates is small, with the domain-averaged NIC showing a degradation of 0.21 . Regionally, improvements in NIC are seen over the Arkansas-Red and parts of the lower Colorado and upper Mississippi basins, and degradations are seen in the western U.S. basins and parts of the upper Missouri basin. Data assimilation provides little added impact over most of the eastern United States and the West Coast. The top three panels of Fig. 5 show the NIC values stratified for three time periods that primarily represent the assimilation of SMMR and SSM/I (1979-2002); AMSR-E and ASCAT (2003-09); and ASCAT, SMOS, SMAP, and AMSR2 (2010-15). During the 1979-2002 time period, the impact of assimilation is small and often disadvantageous, with degradations seen over the western U.S. basins. The use of AMSR-E and ASCAT improves the streamflow estimates during the 2003-09 time period, where enhancements in streamflow are observed over the upper Missouri, Arkansas-Red, and upper Mississippi. Additional improvements in streamflow are observed over regions such the southeastern and northeastern United States during the 2010-15 time period. Though the overall evaluation (1979-2015) is dominated by the SMMR and SSM/I time period (1979-2002), it is encouraging to see more significant improvements in streamflow with the use of newer sensor EDRs. The streamflow evaluation also indicates consistent degradations over the western U.S. basins, suggesting that the remote sensing EDRs may need improvements over these areas. It is also likely that the deficiencies in the data assimilation configuration may be contributing to the degradations from DA over these areas.

The NIC metric, instead of a simple difference metric, is used to quantify the impact of DA on streamflow, as the magnitude and skill of the streamflow varies significantly depending on the basin. The NIC metric helps to present a normalized representation of improvements and degradations in streamflow across the modeling domain. The focus here is to quantify the changes due to DA, though the underlying skill of the streamflow simulation could still be poor, as noted in prior studies (Lohmann et al. 2004; Xia et al. 2012b; Kumar et al. 2014).

\section{d. ET evaluation}

The NCA-LDAS ET estimates are evaluated by comparing them to three ET products: 1 ) the $1 / 2^{\circ}$ gridded ET estimates based on eddy covariance FLUXNET measurements processed through a multitree ensemble (MTE) approach (available monthly from 1982 to 2009; Jung et al. 2009), 2) 4-km resolution thermal-infraredbased ET estimates from the Atmosphere-Land Exchange Inverse (ALEXI; available daily from 2001; Anderson et al. 2007) model, and 3) 5-km-resolution MODIS-based ET estimates from the University of Washington (UW; available monthly from 2003 to 2009; Tang et al. 2009). Note that none of these products can be considered "truth," because all involve significant and imperfect model/calibration assumptions, and unlike the NCA-LDAS estimates, they are not constrained by the water balance.

Nevertheless, Fig. 6 shows difference maps using RMSE [RMSE(OL) - RMSE(DA)] and anomaly $R$ [anomaly $R(\mathrm{DA})$ - anomaly $R(\mathrm{OL})]$ metrics based on comparisons to the three reference datasets (computed across the available data period of each dataset). Overall, the RMSE differences between the OL and NCA-LDAS estimates are small, with the most prominent differences observed over locations with significant application of irrigation, including parts of the Great Plains, central California, and lower Mississippi. All three comparisons show that the ET estimates from NCA-LDAS are improved relative to the OL over central California, though at the domainaveraged scale, the improvements are marginal (0.1, 1.2, and $3.5 \mathrm{~W} \mathrm{~m}^{-2}$ compared to FLUXNET, ALEXI, and UW, respectively). Over the irrigated areas in the central plains, the results are mixed. The FLUXNET MTE and ALEXI evaluations mostly show increased RMSEs for NCA-LDAS, whereas the UW comparison indicates improvements in the NCA-LDAS ET. Both comparisons indicate small improvements over the lower Mississippi region. These trends are also observed in the anomaly $R$ comparisons. Overall, the anomaly $R$ values decrease over the irrigated areas relative to the OL, with more 

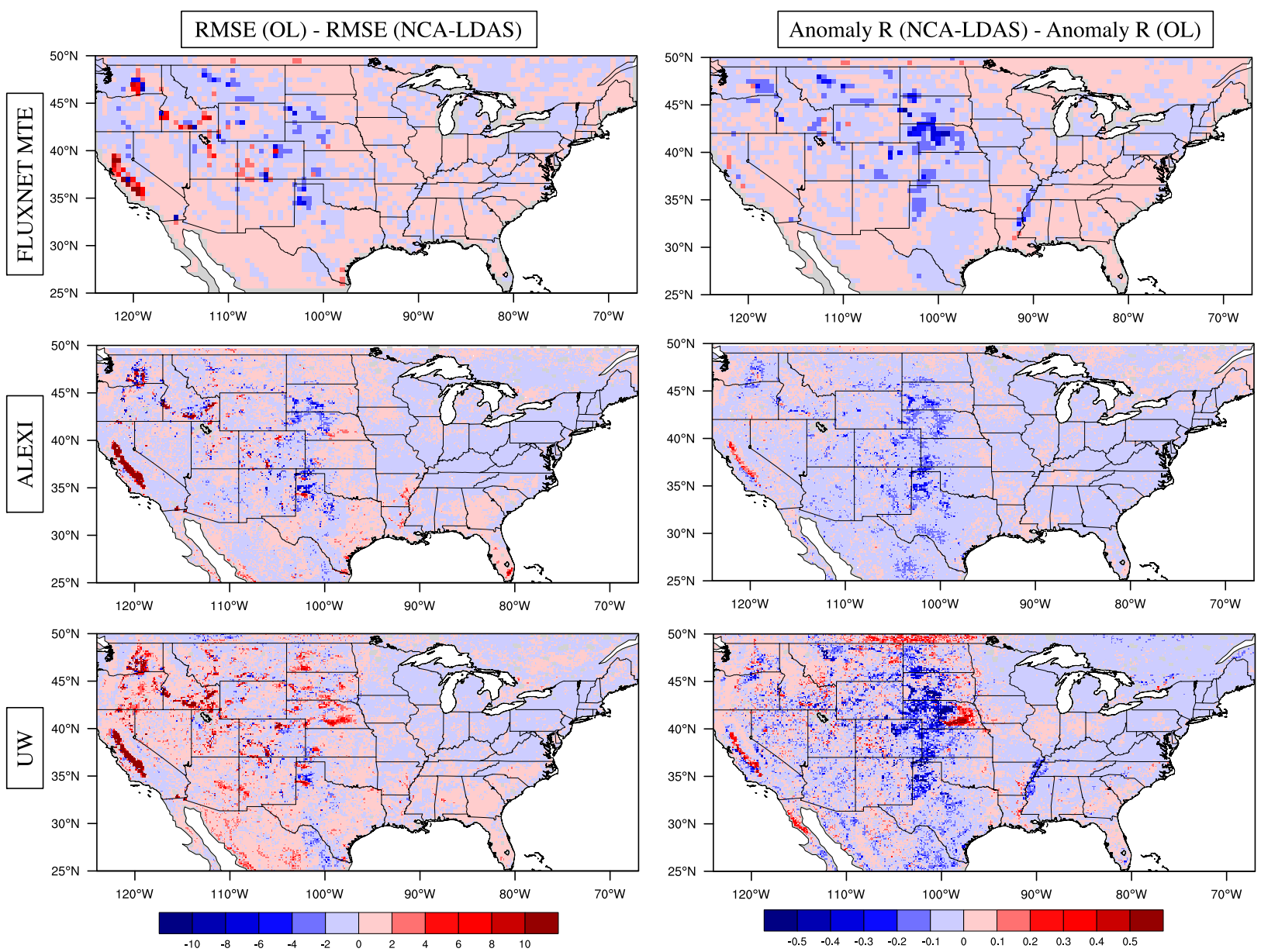

FIG. 6. Comparison of the improvements in evapotranspiration (left) RMSE ( $\mathrm{W} \mathrm{m}^{-2}$ ) and (right) anomaly $R$ using the FLUXNET MTE (19822009), ALEXI (2001-15), and UW (2003-09) reference datasets. The warm and cool colors indicate improvements and degradations from DA, respectively.

prominent degradations observed in the comparisons against the UW datasets. Overall, these comparisons reflect the inherent biases in each of these reference datasets and the difficulties involved in properly evaluating ET estimates over irrigated agricultural areas.

\section{e. Estimates of irrigated water use}

As noted earlier, NCA-LDAS computes the irrigation water use or requirement over the agricultural landscapes over the CONUS. Figure 7 shows a map of the average annual water use and the average seasonal cycle of irrigation water requirements for the CONUS and three different regions of the United States. Similar to the spatial patterns of irrigation reported in Ozdogan et al. (2010), the NCA-LDAS also shows high average irrigation water use estimates over regions such as the plains of Nebraska, central California, the lower Mississippi, and parts of Pacific Northwest. The agricultural regions of the central United States $\left(110^{\circ}-95^{\circ} \mathrm{W}\right)$ have the largest estimated irrigation requirements, followed by the western $\left(124^{\circ}-110^{\circ} \mathrm{W}\right)$ and eastern $\left(95^{\circ}-67^{\circ} \mathrm{W}\right)$ United States. The average irrigation requirements estimated by the NCA-LDAS are smaller than the corresponding estimates for the year 2003 reported by Ozdogan et al. (2010) because of a number of factors. First, there is significant interannual variability in the irrigation water requirements due to changing precipitation, temperature, and demand for different crops, and in the sum the requirements for 2003 (not shown) were relatively large. Second, the short-term changes in soil moisture caused by the assimilation updates likely reduce the simulated application of irrigation. The evaluation of simulated ET estimates presented in section $3 \mathrm{~d}$ suggests that the irrigation water requirements from NCA-LDAS are reasonable, as larger water use 

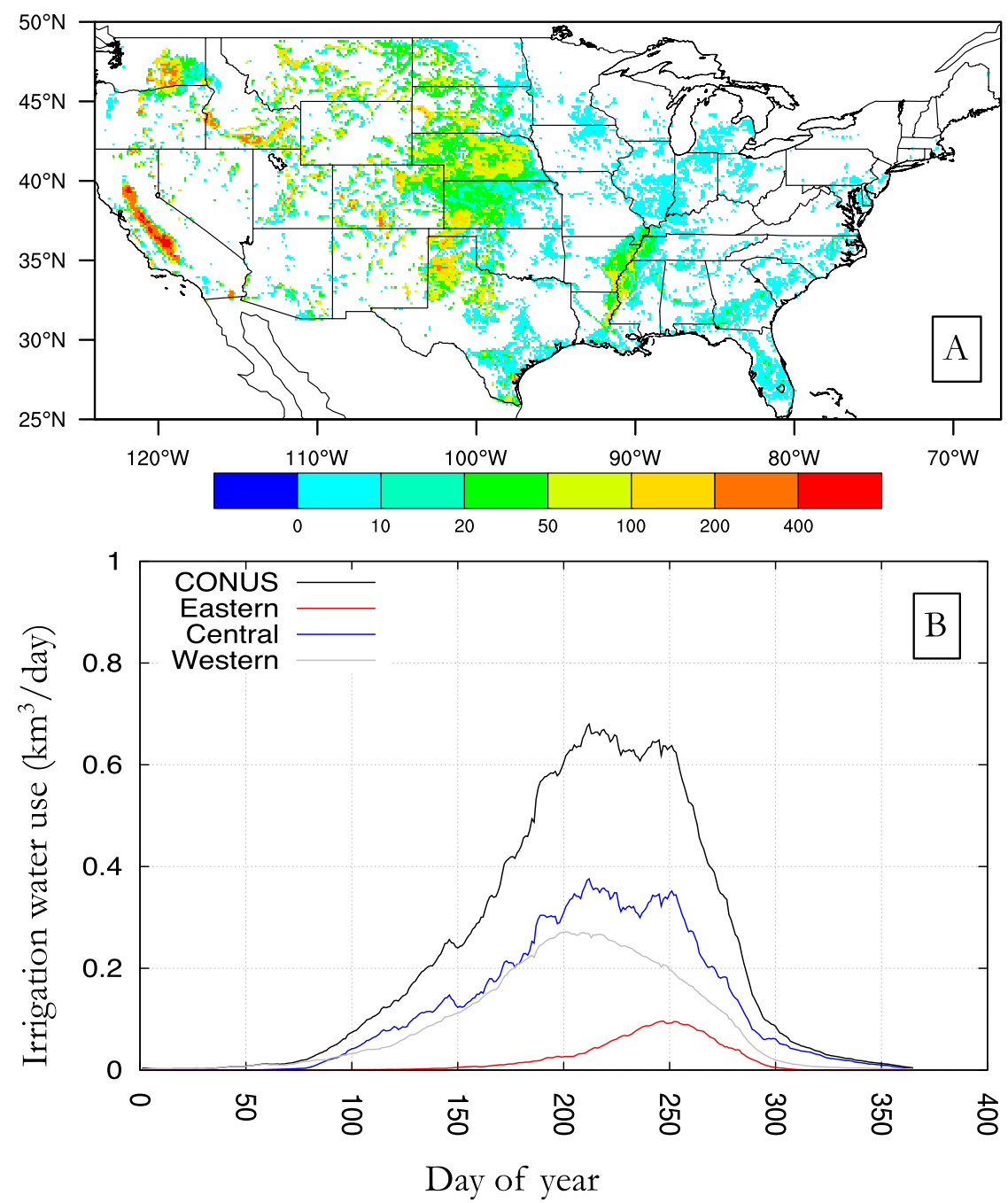

FIG. 7. (a) Spatial distribution of the average annual irrigated water use $\left(\mathrm{mm} \mathrm{yr}^{-1}\right)$ and (b) average seasonal cycle of modeled daily total irrigation amounts $\left(\mathrm{km}^{3} \mathrm{day}^{-1}\right)$ accumulated over the CONUS and the eastern $\left(95^{\circ}-67^{\circ} \mathrm{W}\right)$, central $\left(110^{\circ}-95^{\circ} \mathrm{W}\right)$, and western $\left(124^{\circ}-110^{\circ} \mathrm{W}\right)$ United States.

applications will lead to higher ET estimates in NCALDAS.

\section{f. Comparison to LSM products}

In this section, the skill of soil moisture, snow depth, ET, and total runoff estimates from NCA-LDAS is compared against those from a number of other LSM products, including the Modern-Era Retrospective Analysis for Research and Applications version 2 (MERRA-2; Reichle et al. 2017), ERA-Interim-Land (Balsamo et al. 2015), NLDAS-2 (Xia et al. 2012a), and GLDAS version 1 (GLDAS1; Rodell et al. 2004). As the NLDAS and GLDAS projects employ multiple LSMs, we use the outputs from three LSMs in NLDAS-2 (Noah, Mosaic, and VIC) and GLDAS1 (Noah, Mosaic, and CLM2). The surface soil moisture estimates from each of these eight LSM products are compared against the in situ SCAN soil moisture measurements. Similarly, the snow depth skills are evaluated by comparing them against CMC, comparing ET against FLUXNET MTE, and comparing streamflow against the USGS gauge measurements. Note that the snow depth evaluation does not include GLDAS1, which provides snow water equivalent, but not snow depth.

Figure 8 presents the distribution of skill metrics (using anomaly $R$ for surface soil moisture, RMSE for snow depth, $R$ for total runoff, and RMSE for ET) for the eight LSM products and NCA-LDAS. Generally, the NCALDAS estimates provide consistently high skills for these water budget components. NCA-LDAS-based 

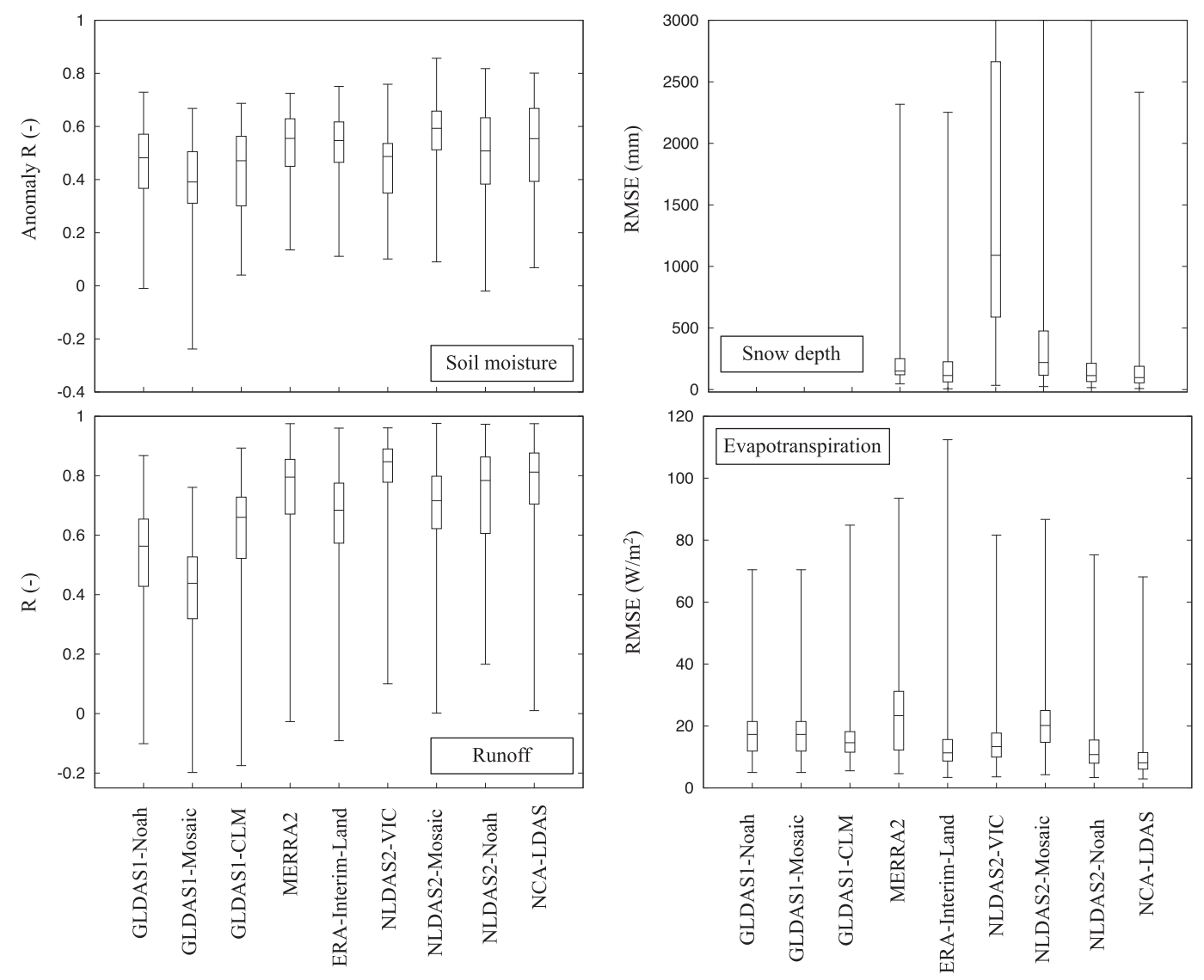

FIG. 8. Box plot comparison of surface soil moisture, snow depth, runoff, and evapotranspiration skills from eight LSM products and NCA-LDAS.

estimates show the best median skills for snow depth and ET. For surface soil moisture and total runoff, the median skill is highest for NLDAS2-Mosaic and NLDAS2-VIC, respectively, followed by NCA-LDAS. Note that the NLDAS2-Noah is closest to the NCA-LDAS in terms of the model configuration and that NCALDAS consistently shows higher skill than NLDAS2Noah in these comparisons. Further, none of the eight LSM products consistently show high skill across the evaluations of different water budget terms. For example, the NLDAS2-VIC shows high skill for simulating total runoff and ET, but low skill for soil moisture and snow depth. Similarly, the ERA-Interim-Land skill is high for soil moisture, ET, and snow depth, but low for total runoff. On the other hand, the NCA-LDAS estimates show consistently high skill in all these evaluations.

\section{NCA-LDAS based drought indicators}

The evaluation of the NCA-LDAS outputs presented in the previous section indicates that the concurrent assimilation of land remote sensing EDRs provides beneficial enhancements in improving key terrestrial water budget components such as soil moisture, snow depth, and streamflow over the CONUS. In this section, we evaluate the utility of NCA-LDAS toward the estimation of climate-relevant water availability indicators for the monitoring and assessment of droughts. We focus on the estimation of drought as LDAS outputs are often used to support retrospective assessments and experimental monitoring of drought conditions (Houborg et al. 2012; Xia et al. 2014; Kumar et al. 2014; Li and Rodell 2015; Kumar et al. 2016).

Physical-process-based typology of droughts usually classifies them into three types: meteorological drought representing precipitation deficits, agricultural drought related to soil moisture deficits, and hydrological drought resulting from streamflow shortages (Keyantash and Dracup 2002; Mo 2008; Shukla and Wood 2008). Drought estimates are typically computed through normalized indices that capture the deficits of the relevant variable (e.g., precipitation, soil moisture, streamflow) from average conditions. Numerous metrics for drought measurement have been developed (Heim 2002), each 
with its own strengths and limitations. Here we compute drought estimates through percentile-based indices used in the NLDAS drought monitoring system (Ek et al. 2011; Sheffield et al. 2012). The percentiles are calculated based on the NCA-LDAS root-zone soil moisture estimates by first assembling the 36-yr climatology and then by calculating the daily percentile values by ranking each day's soil moisture estimate against the climatology, including a 5-day moving window. As before, the root zone is defined as the top $1 \mathrm{~m}$ of soil.

Drought events of varying intensity are classified based on different thresholds for these metrics. Consistent with the categorization used in the U.S. Drought Monitor (USDM; Svoboda et al. 2002) maintained by the National Drought Mitigation Center (NDMC), drought intensity is classified into five categories: D0 (abnormally dry, percentile $\leq 30$ ), D1 (moderate drought, percentile $\leq 20$ ), D2 (severe drought, percentile $\leq 10)$, D3 (extreme drought, percentile $\leq 5$ ), and D4 (exceptional, percentile $\leq 2$ ). The digitized, weekly categorical drought intensity maps from the USDM (available from 2000 onward) are used for comparison to the NCA-LDAS percentile-based drought indices.

As discussed in Tallaksen et al. (1997) and Byun and Wilhite (1999), the characterization of drought events must also consider consecutive occurrences of deficits indicated by the drought indices. As shown in Fig. 9, drought severity $S_{i}$ is defined as the total deficit volume associated with a drought event $i$ (Thomas et al. 2014). The consecutive length of time under deficit is defined as the drought duration $D_{i}$, and the elapsed time between such mutually exclusive drought events defines the frequency of drought. Using these definitions, we characterize drought events at each grid point across the entire NCA-LDAS time period to examine the trends in drought severity and duration. Drought percentiles are computed using the NCA-LDAS outputs during the 1979-2015 time period and consecutive drought occurrences are grouped together to calculate the associated drought severity and duration. The severity for a given drought $S_{i}$ is computed as

$$
S_{i}=\sum_{k=1}^{L}\left(1-p_{k}\right)
$$

where $L$ is the duration of drought (in days), and $p_{k}$ is the drought percentile for day $k$. The average drought duration $\bar{D}$ and severity $\bar{S}$ are then computed across all drought events $N$ during the entire simulation period.

Figure 10 shows maps of average drought duration from the NCA-LDAS and the USDM and the average drought severity from NCA-LDAS over the CONUS. For simplicity, we focus primarily on the D2 drought

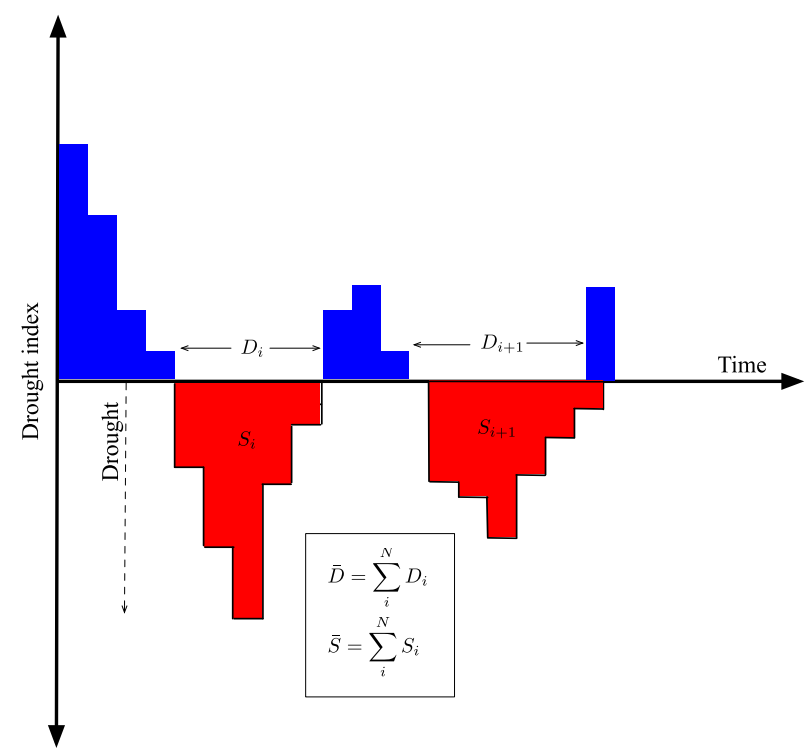

FIG. 9. Schematic of drought events, where consecutive drought occurrences are grouped together. Drought severity $S_{i}$ is the total deficit volume associated with a drought event $i$ and the consecutive length of time under deficit is defined as the drought duration $D_{i}$.

category, as it also represents the threshold of the severe drought classification. The USDM estimates are based on the archived weekly reports of drought intensities (D0-D4), which are available only from the year 2000 onward. In these maps, the average drought duration is expressed in days. Note that as USDM only provides the drought category values, the calculation of drought deficit volume yields the exact same spatial patterns as that of the average drought duration map. In other words, within a certain drought category, further discrimination of drought intensity is not possible from USDM. Therefore, we exclude the comparison of drought severity from USDM. On the other hand, the drought deficit volume for NCA-LDAS is calculated based on the (continuous) percentile values.

Figure 10 essentially maps the water-stressed regions of the United States based on the patterns of agricultural drought distribution from NCA-LDAS and drought quantification from the USDM. In Fig. 10, there is a general contrast between the eastern and western United States with more severe and more long-lasting droughts occurring in the western United States. The comparison of the drought intensities from NCA-LDAS and USDM is meant to be qualitative, due to a number of differences between the two estimates. As noted above, the USDM estimates are categorical (between D0 and D4), whereas the NCA-LDAS estimates provide nondiscrete percentile values. The NCA-LDASbased drought intensity maps are estimated solely using 


\section{NCA-LDAS}
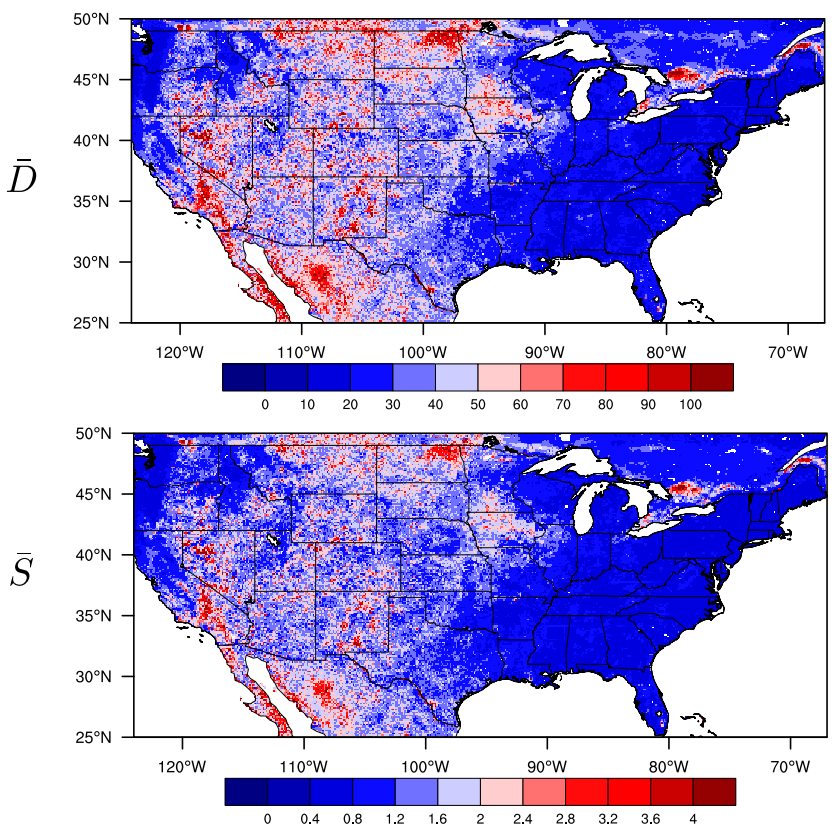

USDM

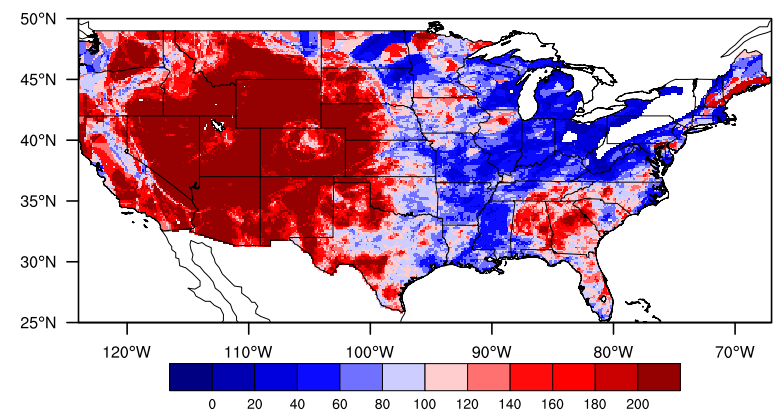

FIG. 10. Maps of average drought duration (days) and average drought severity from NCA-LDAS (based on root-zone soil moisture percentiles) and USDM. root-zone soil moisture, whereas the USDM estimates are generated using a blend of drought indicators from several sources as well as subjective inputs from analysts (Svoboda et al. 2002). The average drought duration and severity maps that we calculated from USDM data are based on a shorter time period of record (2000-15) compared to that of NCA-LDAS. The drought intensities from USDM are computed based on weekly averages, whereas the NCA-LDAS estimates are based on daily drought percentiles, allowing for more granularity in the drought event categorizations. As discussed above, the use of the percentiles also allows for more granularity in the deficit volume calculations. Overall, the average drought duration from the USDM is generally higher, likely due to the reasons mentioned above. Despite these differences, the comparison in Fig. 10 confirms that the climatological trends in drought duration and severity from NCA-LDAS are generally consistent with those reported in USDM. Note also that we purposely do not make an attempt to reconcile the temporal span differences between NCA-LDAS and USDM, as the goal here is to quantify and report the overall trends from NCA-LDAS for the entire 36-yr time period.

Figures 11 and 12 show time series of average drought duration and severity (and their linear trend lines), respectively, computed on an annual basis from 1979 to 2015 for six NCA regions for the D2 drought category (the USDM-based drought severity calculations are omitted). The temporal trends are computed for six geographical regions (Northeast, Southeast, Midwest, Great Plains, Southwest, and Northwest) over the CONUS, as defined in the Third NCA (Melillo et al. 2014, chapters 16-21). In Fig. 11, there is a trend of increasing annual drought duration in all regions except over the Northeast. The lack of a positive trend in drought intensity over the Northeast is likely related to the reported trend of increased heavy precipitation events over this region in the Third NCA. Similar trends in the annual drought duration were observed for all drought categories (not shown), though the slope of the trend lines generally decreases for more extreme categories. Among the NCA regions, the trend-line slopes are highest over the Southwest region, followed by Northwest and Southeast. Over the Midwest and Great Plains, there are marginal increases in the trend-line slopes. As the USDM data encompass a shorter time period, a direct comparison of the trend lines from NCA-LDAS and USDM is difficult. The interannual patterns are generally consistent between NCA-LDAS and USDM, especially over the Southwest, Northwest, Midwest, and Southeast regions. Over the Northeast, the average drought duration (and intensities) is more magnified for drought events in the early 2000s in USDM whereas NCA-LDAS shows comparable drought intensities for events post-2000. Similarly, NCA-LDAS shows larger drought duration for 2014-15 droughts over the Great Plains compared to that of USDM. The patterns in Fig. 12 indicate that the annual average 

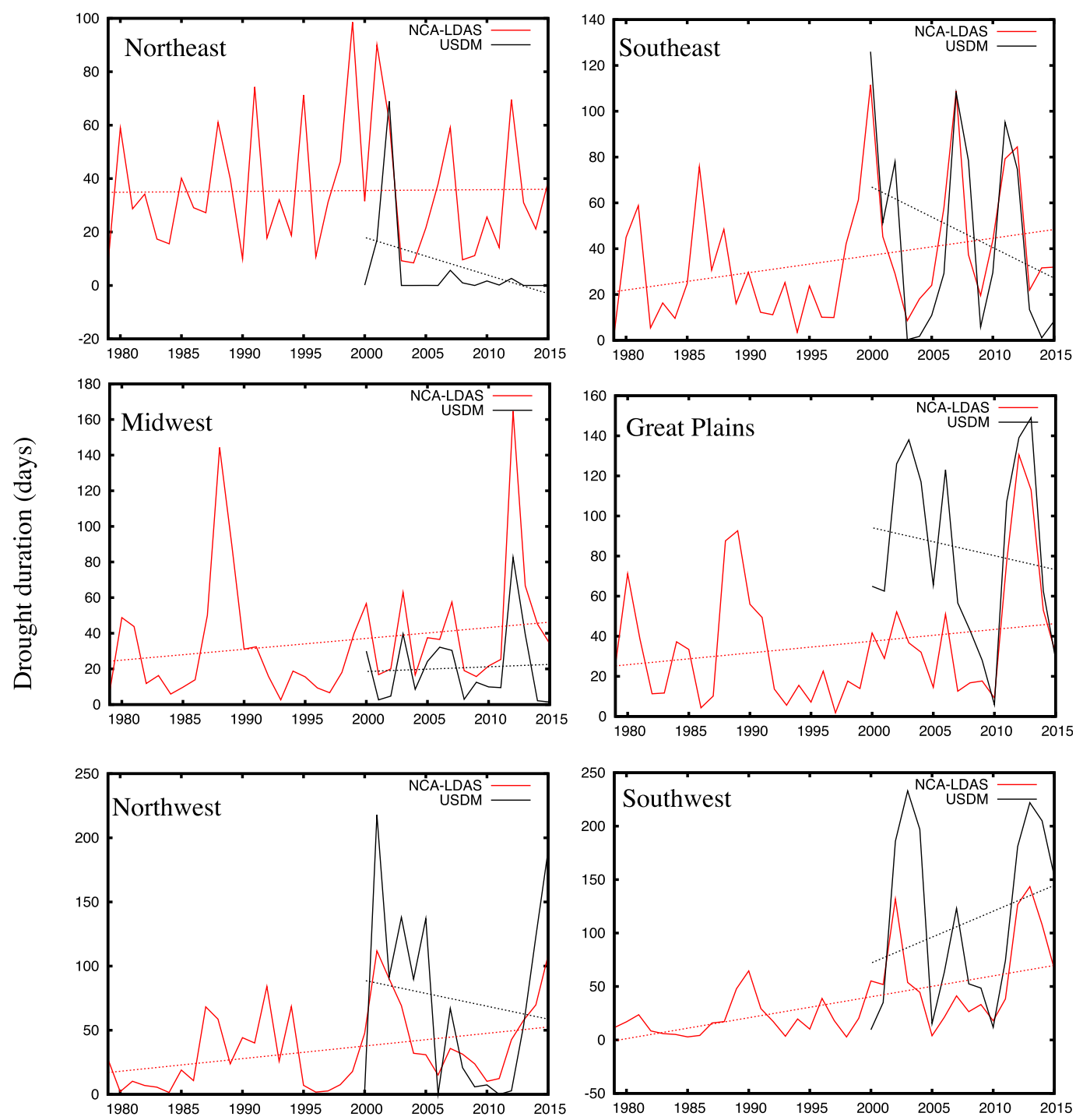

FIG. 11. Time series of average annual drought duration (solid lines) and the corresponding linear trend line (dotted lines) from NCA-LDAS (based on the root-zone soil moisture percentiles) and USDM (for drought category D2), shown for six geographical regions (Northeast, Southeast, Midwest, Great Plains, Southwest, and Northwest) over the CONUS.

severity of droughts also shows increasing trends in most regions, more prominently over the Southwest, Northwest, and Southeast. The trend of increasing drought severity is less prominent for more extreme drought categories (not shown).

\section{Summary and conclusions}

This article describes the development and performance of the NCA-LDAS, which is an offline terrestrial land analysis developed as an enabling tool for the NCA. NCA-LDAS is built upon NASA's LIS software framework, employing the Noah land surface model and the HyMAP streamflow routing model forced with the NLDAS-2 meteorology. Importantly, NCALDAS is one of the first successful examples of a landoriented multivariate data assimilation analysis that simultaneously incorporates satellite-based EDRs of soil moisture, snow depth, snow cover, and irrigation intensity. Soil moisture EDRs from SMMR, SSM/I, AMSR-E, ASCAT, SMOS, and SMAP and snow depth EDRs from SMMR, SSM/I, AMSR-E, and AMSR2 are employed in the analysis using a one-dimensional EnKF. Snow cover EDRs from the IMS product and MODIS are employed as snow detection constraints for the passive microwave snow depth assimilation. MODIS-based 

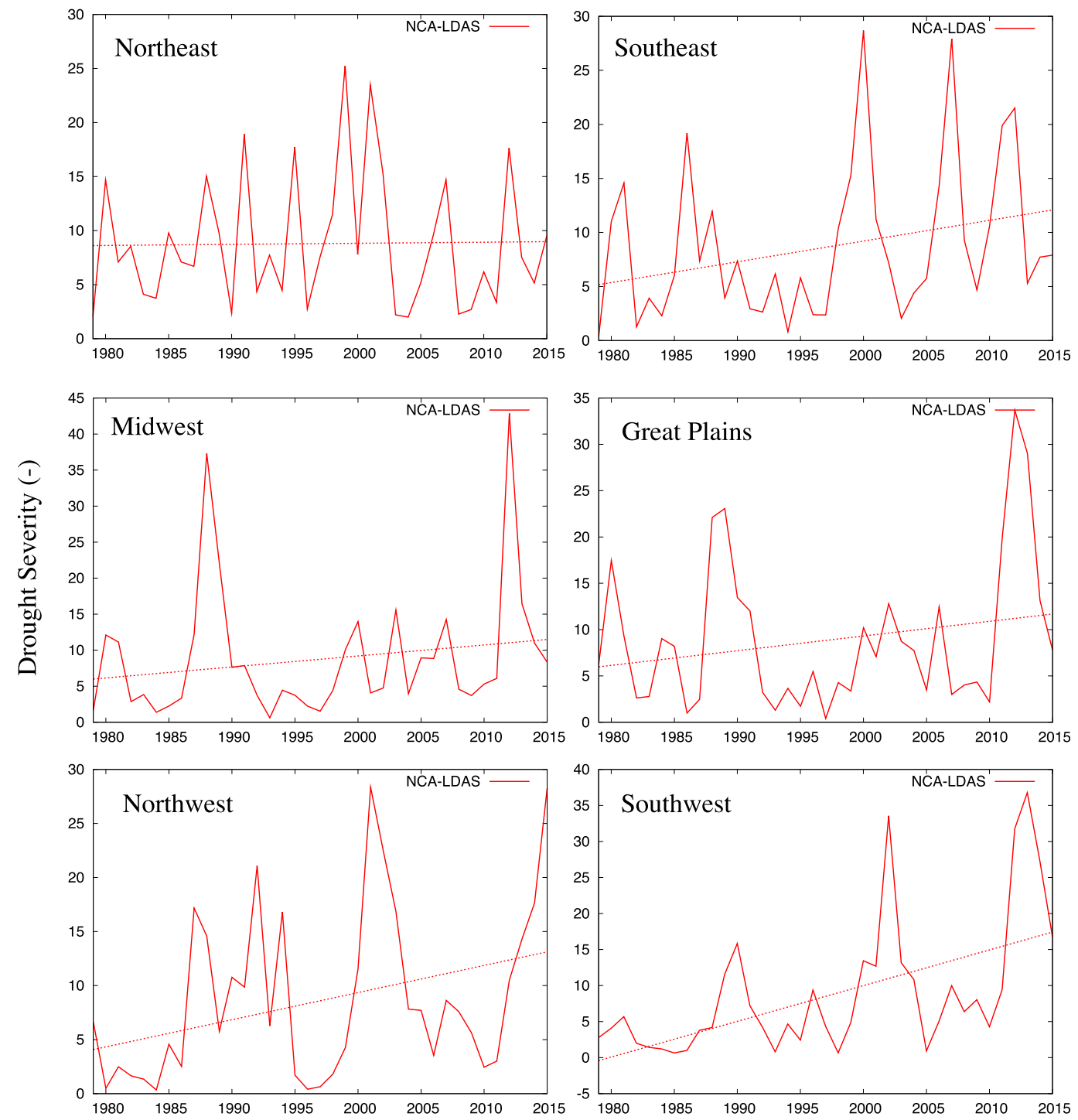

FIG. 12. As in Fig. 11, but for average annual drought severity. The drought deficit volume for NCA-LDAS is computed based on percentile values.

irrigation intensity estimates are used to simulate a demand-driven irrigation scheme to incorporate representations of human managed landscapes.

The added impact of the multivariate land analysis is evaluated by comparing it against a large suite of reference data products. The soil moisture enhancements from DA were evaluated by comparing them against in situ measurements from USDA ARS, SCAN, and USCRN. The overall impact from data assimilation of various soil moisture EDRs on improving surface and root-zone soil moisture skills is small and regionally dependent. The soil moisture skills showed improvements over regions such as the Great Plains and the Arkansas-Red and lower Mississippi basins with degradations over the southwestern United States. When the changes in soil moisture skills are stratified temporally, larger improvements are seen in most regions during the 2010-15 time period, indicating the beneficial impact of modern soil moisture sensors and EDRs. These improvements can be attributed to the improved quality and frequency of the sensors and improvements to the retrieval algorithms. The retrievals from the older sensors are from the $\mathrm{Ku}, \mathrm{X}$, and $\mathrm{C}$ bands, whereas SMOS and SMAP retrievals are from $\mathrm{L}$ band, which is known to have improved sensitivity for soil moisture detection (Xu et al. 2017). The snow depth estimates from NCA-LDAS showed improved skill over the OL estimates when evaluated against the CMC and SNODAS datasets. The use of AMSR-E and AMSR2 retrievals are found to provide more significant 
improvements within DA compared to that of SMMR and SSM/I. Though the overall impact of multivariate DA on streamflow (compared to USGS gauge measurements) is small, larger improvements in streamflow are observed with the use of newer sensor EDRs. Over the western U.S. basins, the impact of DA on streamflow is mostly disadvantageous, suggesting a possible need for improving the remote sensing retrievals over these regions. The ET estimates from NCA-LDAS showed the most significant differences compared to the OL over irrigated areas in central California, the Great Plains, and lower Mississippi. The skill of NCA-LDAS estimates of soil moisture, snow depth, ET, and runoff is compared against that from eight other LSM products. Generally, the NCA-LDAS products are found to have high skill for these key water budget terms.

The article also explores the utility of the NCA-LDAS simulation outputs for drought monitoring and assessment using root-zone soil-moisture-based percentiles. The consecutive drought occurrences are grouped together to compute the trends in drought severity and drought duration. Similar metrics are computed using the digitized data from the USDM. The results show that relative to the eastern United States, more severe and longer-lasting droughts occur over the western United States, consistent with the trends seen from USDM. The temporal trends in annual drought duration and severity also show an increasing trend in most regions of the United States, except over the Northeast, where there is a decreasing trend. The most prominent trend of increasing average drought duration and severity is seen over the southwestern United States.

The results presented in this article demonstrate that the assimilation of terrestrial land remote sensing products within NCA-LDAS provides a high-quality, firstof-its-kind multivariate land analysis. The integrated terrestrial water analysis from NCA-LDAS provides a comprehensive, observation-informed data product to the community for developing climate indicators for water fluxes and states. The multivariate data assimilation enhancements and capabilities developed through this effort are also expected to augment near-real-time LDAS efforts such as GLDAS and NLDAS and applications such as drought monitoring that rely on the outputs from these systems.

Acknowledgments. Funding for this work was provided by the NASA Science Mission Directorate's Earth Science Division through the NCA project and NOAA's Climate Program Office MAPP program (Grant GC14-194A). Computing was supported by the resources at the NASA Center for Climate Simulation. The NLDAS-2 forcing data used in this effort were acquired as part of the activities of NASA's Science Mission Directorate and are archived and distributed by the Goddard Earth Sciences (GES) Data and Information Services Center (DISC). We are grateful to Dr. Michael Cosh (USDA ARS) for providing the USDA ARS soil moisture datasets, Dr. Martha Anderson (USDA ARS) and Dr. Christopher Hain (NASA MSFC) for the ALEXI datasets, and Jonathan Case (NASA MSFC) and Jordan Bell (NASA MSFC) for the digitized archive of USDM.

\section{REFERENCES}

Anderson, M., J. Norman, J. Mecikalski, J. Otkin, and W. Kustas, 2007: A climatological study of evapotranspiration and moisture stress across the continental United States based on thermal remote sensing: 1. Model formulation. J. Geophys. Res., 112, D10117, https://doi.org/10.1029/2006JD007506.

Baldwin, M., and K. E. Mitchell, 1997: The NCEP hourly multisensor U.S. precipitation analysis for operations and GCIP research. Preprints, 13th Conf. on Hydrology, Long Beach, CA, Amer. Meteor. Soc., 54-55.

Balsamo, G., and Coauthors, 2015: ERA-Interim/Land: A global land surface reanalysis data set. Hydrol. Earth Syst. Sci., 19, 389-407, https://doi.org/10.5194/hess-19-389-2015.

Barbu, A. L., J.-C. Calvet, J.-F. Mahfouf, and S. Lafont, 2014: Integrating ASCAT surface soil moisture and GEOV1 leaf area index into the SURFEX modelling platform: A land data assimilation application over France. Hydrol. Earth Syst. Sci., 18, 173-192, https://doi.org/10.5194/hess-18-173-2014.

Barrett, A., 2003: National Operational Hydrologic Remote Sensing Center Snow Data Assimilation System (SNODAS) products at NSIDC. NSIDC Special Rep. 11, 19 pp., https:// nsidc.org/sites/nsidc.org/files/files/nsidc_special_report_11.pdf.

Bell, J., and Coauthors, 2013: U.S. Climate Reference Network soil moisture and temperature observations. J. Hydrometeor., 14, 977-988, https://doi.org/10.1175/JHM-D-12-0146.1.

Bolten, J., W. Crow, X. Zhan, T. Jackson, and C. Reynolds, 2009: Evaluation of a soil moisture data assimilation system over West Africa. 2009 IEEE Int. Geoscience and Remote Sensing Symp., Vol. 2, Cape Town, South Africa, IEEE, 976-979, https://doi.org/10.1109/IGARSS.2009.5418264.

Bosilovich, M. G., F. R. Robertson, L. Takacs, A. Molod, and D. Mocko, 2017: Atmospheric water balance and variability in the MERRA-2 reanalysis. J. Climate, 30, 1177-1196, https:// doi.org/10.1175/JCLI-D-16-0338.1.

Brown, R., and B. Brasnett, 2010: Canadian Meteorological Centre (CMC) daily snow depth analysis data, version 1 (updated annually). [Data over the model domain (25-53 N, 125-67 W), during 1998-2015.] NASA National Snow and Ice Data Center Distributed Active Archive Center, accessed June 2016, https://doi.org/10.5067/W9FOYWH0EQZ3.

Buizer, J. L., and Coauthors, 2016: Building a sustained climate assessment process. Climatic Change, 135, 23-37, https:// doi.org/10.1007/s10584-015-1501-4.

Byun, H., and D. Wilhite, 1999: Objective quantification of drought severity and duration. J. Climate, 12, 2747-2756, https://doi.org/ 10.1175/1520-0442(1999)012<2747:OQODSA>2.0.CO;2.

Chang, A., J. Foster, and D. Hall, 1987: Nimbus-7 SMMR derived global snow cover parameters. Ann. Glaciol., 9, 39-44, https:// doi.org/10.1017/S0260305500000355. 
Cressman, G., 1959: An operational objective analysis system. Mon. Wea. Rev., 87, 367-374, https://doi.org/10.1175/ 1520-0493(1959)087<0367:AOOAS > 2.0.CO;2.

Daly, C., R. Neilson, and D. Phillips, 1994: A statistical-topographic model for mapping climatological precipitation over mountainous terrain. J. Appl. Meteor., 33, 140-158, https://doi.org/ 10.1175/1520-0450(1994)033<0140:ASTMFM > 2.0.CO;2.

Dee, D., and A. da Silva, 1998: Data assimilation in the presence of forecast bias. Quart. J. Roy. Meteor. Soc., 124, 269-295, https:// doi.org/10.1002/qj.49712454512.

de Lannoy, G. J. M., R. H. Reichle, K. R. Arsenault, P. R. Houser, S. Kumar, N. E. C. Verhoest, and V. R. N. Pauwels, 2012: Multiscale assimilation of Advanced Microwave Scanning Radiometer-EOS snow water equivalent and Moderate Resolution Imaging Spectroradiometer snow cover fraction observations in northern Colorado. Water Resour. Res., 48, W01522, https://doi.org/10.1029/2011WR010588.

_ , P. D. Rosnay, and R. Reichle, 2015: Soil moisture data assimilation. Handbook of Hydrometeorological Ensemble Forecasting, Q. Duan et al., Eds., Springer, 1-43, https:// doi.org/10.1007/978-3-642-40457-3_32-1

de Rosnay, P., G. Balsamo, C. Albergel, J. Munoz-Sabater, and L. Isaksen, 2014: Initialisation of land surface variables for Numerical Weather Prediction. Surv. Geophys., 35, 607-621, https://doi.org/10.1007/s10712-012-9207-x.

Diamond, H., and Coauthors, 2013: U.S. Climate Reference Network after one decade of operations: Status and assessment. Bull. Amer. Meteor. Soc., 94, 485-498, https://doi.org/10.1175/ BAMS-D-12-00170.1.

Dorigo, W., and Coauthors, 2017: ESA CCI Soil Moisture for improved Earth system understanding: State-of-the art and future directions. Remote Sens. Environ., 203, 185-215, https:// doi.org/10.1016/j.rse.2017.07.001.

Dziubanski, D. J., and K. J. Franz, 2016: Assimilation of AMSR-E snow water equivalent data in a spatially-lumped snow model. J. Hydrol., 540, 26-39, https://doi.org/10.1016/j.jhydrol.2016.05.046.

Ek, M., K. Mitchell, L. Yin, P. Rogers, P. Grunmann, V. Koren, G. Gayno, and J. Tarpley, 2003: Implementation of Noah land surface model advances in the National Centers for Environmental Prediction operational mesoscale Eta model. J. Geophys. Res., 108, 8851, https://doi.org/10.1029/ 2002JD003296.

— , and Coauthors, 2011: North American Land Data Assimilation System Phase 2 (NLDAS-2): Development and applications. GEWEX News, Vol. 21, No. 2, International GEWEX Project Office, Silver Spring, MD, 6-7, https://www.gewex.org/ gewex-content/files_mf/1432209506May2011.pdf.

Entekhabi, D., R. Reichle, R. Koster, and W. Crow, 2010: Performance metrics for soil moisture retrievals and application requirements. J. Hydrometeor., 11, 832-840, https://doi.org/ 10.1175/2010JHM1223.1.

Fairbairn, D., A. L. Barbu, A. Napoly, C. Albergel, J.-F. Mahfouf, and J.-C. Calvet, 2017: The effect of satellite-derived surface soil moisture and leaf area index land data assimilation on streamflow simulations over France. Hydrol. Earth Syst. Sci. 21, 2015-2033, https://doi.org/10.5194/hess-21-2015-2017.

Fletcher, S. J., G. E. Liston, C. A. Hiemstra, and S. D. Miller, 2012: Assimilating MODIS and AMSR-E snow observations in a snow evolution model. J. Hydrometeor., 13, 1475-1492, https:// doi.org/10.1175/JHM-D-11-082.1.

Getirana, A., A. Boone, D. Yamazaki, B. Decharme, F. Papa, and N. Mognard, 2012: The Hydrological Modeling and Analysis Platform (HyMAP): Evaluation in the Amazon basin.
J. Hydrometeor., 13, 1641-1665, https://doi.org/10.1175/JHMD-12-021.1.

Girotto, M., G. J. M. De Lannoy, R. H. Reichle, and M. Rodell, 2016: Assimilation of gridded terrestrial water storage observations from GRACE into a land surface model. Water Resour. Res., 52, 4164-4183, https://doi.org/ 10.1002/2015WR018417.

Hall, D. K., and G. A. Riggs, 2016: MODIS/Terra Snow Cover Daily L3 Global 0.05deg CMG, version 6. [Data over the model domain (25-53 N, 125-67 W), during 2000-2015.] NASA National Snow and Ice Data Center Distributed Active Archive Center, accessed June 2016, https://doi.org/ 10.5067/MODIS/MOD10C1.006.

Han, E., W. T. Crow, T. Holmes, and J. Bolten, 2014: Benchmarking a soil moisture data assimilation system for agricultural drought monitoring. J. Hydrometeor., 15, 11171134, https://doi.org/10.1175/JHM-D-13-0125.1.

Heim, R., 2002: A review of twentieth-century drought indices used in the United States. Bull. Amer. Meteor. Soc., 83, 11491165, https://doi.org/10.1175/1520-0477-83.8.1149.

Houborg, R., M. Rodell, B. Li, R. Reichle, and B. Zaitchik, 2012: Drought indicators based on model-assimilated Gravity Recovery and Climate Experiment (GRACE) terrestrial water storage observations. Water Resour. Res., 48, W07525, https:// doi.org/10.1029/2011WR011291.

Jackson, T., and Coauthors, 2010: Validation of Advanced Microwave Scanning Radiometer soil moisture products. IEEE Trans. Geosci. Remote Sens., 48, 4256-4272, https://doi.org/ 10.1109/TGRS.2010.2051035.

Jung, M., M. Reichstein, and A. Bondeau, 2009: Towards a global empirical upscaling of FLUXNET eddy covariance observations: Validation of a model tree ensemble approach using a biosphere model. Biogeosciences, 6, 2001-2003.

Kachi, M., K. Naoki, M. Hori, and K. Imaoka, 2013: AMSR2 validation results. 2013 IEEE Int. Geoscience and Remote Sensing Symp., Melbourne, Victoria, Australia, IEEE, 831-834, https://doi.org/10.1109/IGARSS.2013.6721287.

Kalnay, E., and Coauthors, 1996: The NCEP/NCAR 40-Year Reanalysis Project. Bull. Amer. Meteor. Soc., 77, 437-471, https://doi.org/10.1175/1520-0477(1996)077<0437:TNYRP>2.0.CO;2.

Kelly, R., 2009: The AMSR-E snow depth algorithm: Description and initial results. J. Remote Sens. Soc. Jpn., 29, 307-317, https://doi.org/10.11440/rssj.29.307.

_, A. Chang, L. Tsang, and J. Foster, 2003: A prototype AMSRE global snow area and snow depth algorithm. IEEE Trans. Geosci. Remote Sens., 41, 230-242, https://doi.org/10.1109/ TGRS.2003.809118.

Kenney, M. A., A. C. Janetos, and G. C. Lough, 2016: Building an integrated U.S. National Climate Indicators System. Climatic Change, 135, 85-96, https://doi.org/10.1007/s10584-016-1609-1.

Keyantash, J., and J. Dracup, 2002: The quantification of drought: An evaluation of drought indices. Bull. Amer. Meteor. Soc., 83, 1167-1180, https://doi.org/10.1175/1520-0477-83.8.1167.

Koster, R., Z. Guo, R. Yang, P. Dirmeyer, K. Mitchell, and M. Puma, 2009: On the nature of soil moisture in land surface models. J. Climate, 22, 4322-4335, https://doi.org/10.1175/ 2009JCLI2832.1.

Kumar, S. V., and Coauthors, 2006: Land Information System: An interoperable framework for high resolution land surface modeling. Environ. Modell. Software, 21, 1402-1415, https:// doi.org/10.1016/j.envsoft.2005.07.004.

, R. Reichle, C. Peters-Lidard, R. Koster, X. Zhan, W. Crow, J. Eylander, and P. Houser, 2008: A land surface data assimilation 
framework using the Land Information System: Description and applications. Adv. Water Resour., 31, 1419-1432, https://doi.org/ 10.1016/j.advwatres.2008.01.013.

,,-- R. Koster, W. Crow, and C. Peters-Lidard, 2009: Role of subsurface physics in the assimilation of surface soil moisture observations. J. Hydrometeor., 10, 1534-1547, https:// doi.org/10.1175/2009JHM1134.1.

, C. Peters-Lidard, J. Santanello, K. Harrison, Y. Liu, and M. Shaw, 2012a: Land surface Verification Toolkit (LVT)—A generalized framework for land surface model evaluation. Geosci. Model Dev., 5, 869-886, https://doi.org/10.5194/gmd-5869-2012.

, R. Reichle, K. Harrison, C. Peters-Lidard, S. Yatheendradas, and J. Santanello, 2012b: A comparison of methods for a priori bias correction in soil moisture data assimilation. Water Resour. Res., 48, W03515, https://doi.org/10.1029/2010WR010261.

_- and Coauthors, 2014: Assimilation of remotely sensed soil moisture and snow depth retrievals for drought estimation. J. Hydrometeor., 15, 2446-2469, https://doi.org/10.1175/JHM-D-13-0132.1.

_ C. Peters-Lidard, K. Arsenault, A. Getirana, D. Mocko, and Y. Liu, 2015: Quantifying the added value of snow cover area observations in passive microwave snow depth data assimilation. J. Hydrometeor., 16, 1736-1741, https://doi.org/10.1175/ JHM-D-15-0021.1.

_ restrial water storage estimates in the North American Land Data Assimilation System. J. Hydrometeor., 17, 1951-1972, https://doi.org/10.1175/JHM-D-15-0157.1.

Li, B., and M. Rodell, 2015: Evaluation of a model-based groundwater drought indicator in the conterminous U.S. J. Hydrol., 526, https://doi.org/10.1016/j.jhydrol.2014.09.027.

,- , B. Zaitchik, R. Reichle, and R. Koster, 2012: Assimilation of GRACE terrestrial water storage into a land surface model: Evaluation and potential value for drought monitoring in western and central Europe. J. Hydrol., 446-447, 103-115, https://doi.org/10.1016/j.jhydrol.2012.04.035.

Lievens, H., and Coauthors, 2015: SMOS soil moisture assimilation for improved hydrologic simulation in the Murray Darling Basin, Australia. Remote Sens. Environ., 168, 146-162, https:// doi.org/10.1016/j.rse.2015.06.025.

Liu, J., X. Zhan, L. Zhao, K. Jensen, and X. Wang, 2012: NOAA Soil Moisture Operational Product System (SMOPS) and its soil moisture retrieval from AMSR-E and WindSat. 28th Conf. on Hydrology, New Orleans, LA, Amer. Meteor. Soc., 68, https:// ams.confex.com/ams/92Annual/webprogram/Paper199080.html.

Liu, Q., and Coauthors, 2011: The contributions of precipitation and soil moisture observations to the skill of soil moisture estimates in a land data assimilation system. J. Hydrometeor., 12, 750-765, https://doi.org/10.1175/JHM-D-10-05000.1.

Liu, Y., R. Parinussa, W. Dorigo, R. De Jeu, W. Wagner, A. Van Dijk, M. McCabe, and J. Evans, 2011: Developing an improved soil moisture dataset by blending passive and active microwave satellite-based retrievals. Hydrol. Earth Syst. Sci., 15, 425-436, https://doi.org/10.5194/hess-15-425-2011.

Lohmann, D., and Coauthors, 2004: Streamflow and water balance intercomparisons of four land surface models in the North American Land Data Assimilation System Project. J. Geophys. Res., 109, D07S91, https://doi.org/ 10.1029/2003JD003517.

McNally, A., and Coauthors, 2017: A land data assimilation system for sub-Saharan Africa food and water security applications. Sci. Data, 4, 170012, https://doi.org/10.1038/sdata.2017.12.
Melillo, J. M., T. Richmond, and G. Yohe, 2014: Climate change impacts in the United States: The Third National Climate Assessment. U.S. Global Change Research Program Rep., 841 pp., https://doi.org/10.7930/J0Z31WJ2.

Menne, M. J., I. Durre, R. Vose, B. Gleason, and T. Houston, 2012: An overview of the Global Historical Climatology NetworkDaily database. J. Atmos. Oceanic Technol., 29, 897-910, https://doi.org/10.1175/JTECH-D-11-00103.1.

Mesinger, F., and Coauthors, 2006: North American Regional Reanalysis. Bull. Amer. Meteor. Soc., 87, 343-360, https:// doi.org/10.1175/BAMS-87-3-343.

Mitchell, K. E., and Coauthors, 2004: The multi-institution North American Land Data Assimilation System (NLDAS): Utilizing multiple GCIP products and partners in a continental distributed hydrological modeling system. J. Geophys. Res., 109, D07S90, https://doi.org/10.1029/2003JD003823.

Mo, K., 2008: Model-based drought indices over the United States. J. Hydrometeor., 9, 1212-1230, https://doi.org/ 10.1175/2008JHM1002.1.

Njoku, E. G., T. J. Jackson, V. Lakshmi, T. K. Chan, and S. V. Nghiem, 2003: Soil moisture retrieval from AMSR-E. IEEE Trans. Geosci. Remote Sens., 41, 215229, https://doi.org/10.1109/TGRS.2002.808243.

Oki, T., K. Imaoka, and M. Kachi, 2010: AMSR instruments on GCOM-W1/2: Concepts and applications. 2010 IEEE Int. Geoscience and Remote Sensing Symp., Honolulu, HI, IEEE, 1363-1366, https://doi.org/10.1109/IGARSS.2010.5650001.

O’Neill, P., S. Chan, E. Njoku, T. Jackson, and R. Bindlish, 2015: Soil Moisture Active Passive (SMAP) Algorithm Theoretical Basis Document (ATBD): SMAP level 2 \& 3 soil moisture (passive) data products. JPL D-66480, 80 pp., https://smap.jpl. nasa.gov/documents/.

Onogi, K., and Coauthors, 2005: JRA-25: Japanese 25-year reanalysis project-Progress and status. Quart. J. Roy. Meteor. Soc., 131, 3259-3268, https://doi.org/10.1256/qj.05.88.

Owe, M., R. de Jeu, and T. Holmes, 2008: Multisensor historical climatology of satellite-derived global land surface moisture. J. Geophys. Res., 13, F01002, https://doi.org/ 10.1029/2007JF000769.

Ozdogan, M., and G. Gutman, 2008: A new methodology to map irrigated areas using multi-temporal MODIS and ancillary data: An application example in the continental U.S. $R e$ mote Sens. Environ., 112, 3520-3537, https://doi.org/10.1016/ j.rse.2008.04.010.

_ M. Rodell, H. Beudoing, and D. Toll, 2010: Simulating the effects of irrigation over the United States in a land surface model based on satellite-derived agricultural data. J. Hydrometeor., 11, 171-184, https://doi.org/10.1175/2009JHM1116.1.

Peters-Lidard, C. D., and Coauthors, 2007: High-performance Earth System modeling with NASA/GSFC's Land Information System. Innovations Syst. Software Eng., 3, 157-165, https://doi.org/10.1007/s11334-007-0028-x.

Pinker, R. T., and Coauthors, 2003: Surface radiation budgets in support of the GEWEX Continental-Scale International Project (GCIP) and the GEWEX Americas Prediction Project (GAPP), including the North American Land Data Assimilation System (NLDAS) project. J. Geophys. Res., 108, 8844, https://doi.org/10.1029/2002JD003301.

Pipunic, R. C., D. Ryu, and J. P. Walker, 2014: Assessing nearsurface soil moisture assimilation impacts on modeled rootzone moisture for an Australian agricultural landscape. Remote Sensing of the Terrestrial Water Cycle, Geophys. 
Monogr., Vol. 206, Amer. Geophys. Union, 305-317, https:// doi.org/10.1002/9781118872086.ch18.

Ramsay, B., 1998: The interactive multisensor snow and ice mapping system. Hydrol. Processes, 12, 1537-1546, https:// doi.org/10.1002/(SICI)1099-1085(199808/09)12:10/11<1537: AID-HYP679>3.0.CO;2-A.

Reichle, R. H., and R. Koster, 2004: Bias reduction in short records of satellite soil moisture. Geophys. Res. Lett., 31, L19501, https://doi.org/10.1029/2004GL020938.

- D. McLaughlin, and D. Entekhabi, 2002: Hydrologic data assimilation with the ensemble Kalman filter. Mon. Wea. Rev., 130, 103-114, https://doi.org/10.1175/1520-0493(2002)130<0103: HDAWTE $>2.0 . \mathrm{CO}$; .

- , R. D. Koster, P. Liu, S. P. P. Mahanama, E. G. Njoku, and M. Owe, 2007: Comparison and assimilation of global soil moisture retrievals from the Advanced Microwave Scanning Radiometer for the Earth Observing System (AMSR-E) and the Scanning Multichannel Microwave Radiometer (SMMR). J. Geophys. Res., 112, D09108, https://doi.org/ 10.1029/2006JD008033.

_ _ S. Kumar, S. Mahanama, R. Koster, and Q. Liu, 2010: Assimilation of satellite-derived skin temperature observations into land surface models. J. Hydrometeor., 11, 1103-1122, https://doi.org/10.1175/2010JHM1262.1.

—, R. D. Koster, G. J. M. de Lannoy, B. A. Forman, Q. Liu, S. P. P. Mahanama, and A. Toure, 2011: Assessment and enhancement of MERRA land surface hydrology estimates. J. Climate, 24, 6322-6338, https://doi.org/10.1175/JCLI-D-10-05033.1.

—_, C. S. Draper, Q. Liu, M. Girotto, S. P. P. Mahanama, R. D. Koster, and G. J. M. de Lannoy, 2017: Assessment of MERRA-2 land surface hydrology estimates. J. Climate, 30, 2937-2960, https://doi.org/10.1175/JCLI-D-16-0720.1.

Rienecker, M. M., and Coauthors, 2011: MERRA: NASA's Modern-Era Retrospective Analysis for Research and Applications. J. Climate, 24, 3624-3648, https://doi.org/10.1175/ JCLI-D-11-00015.1.

Rodell, M., and Coauthors, 2004: The Global Land Data Assimilation System. Bull. Amer. Meteor. Soc., 85, 381-394, https:// doi.org/10.1175/BAMS-85-3-381.

Saha, S., and Coauthors, 2010: The NCEP Climate Forecast System Reanalysis. Bull. Amer. Meteor. Soc., 91, 1015-1057, https:// doi.org/10.1175/2010BAMS3001.1.

Schaefer, G., M. Cosh, and T. Jackson, 2007: The USDA Natural Resources Conservation Service Soil Climate Analysis Network (SCAN). J. Atmos. Oceanic Technol., 24, 2073-2077, https://doi.org/10.1175/2007JTECHA930.1.

Sheffield, J., Y. Xia, L. Luo, E. Wood, M. Ek, K. Mitchell, and the NLDAS Team, 2012: Drought monitoring with the North American Land Data Assimilation System: A framework for merging model and satellite data for improved drought monitoring. Remote Sensing of Drought: Innovative Monitoring Approaches, B. Wardlow, M. Anderson, and J. Verdin, Eds., Taylor and Francis, 227-260.

Shukla, S., and A. W. Wood, 2008: Use of a standardized runoff index for characterizing hydrologic drought. Geophys. Res. Lett., 35, 102405, https://doi.org/10.1029/2007GL032487.

Soldo, Y., A. Khazaal, F. Cabot, and Y. H. Kerr, 2016: An RFI index to quantify the contamination of SMOS data by radio-frequency interference. IEEE J. Sel. Top. Appl. Earth Obs. Remote Sens., 9, 1577-1589, https://doi.org/ 10.1109/JSTARS.2015.2425542.

Su, H., Z.-L. Yang, R. E. Dickinson, C. R. Wilson, and G.-Y. Niu, 2010: Multisensor snow data assimilation at the continental scale: The value of Gravity Recovery and Climate Experiment terrestrial water storage information. J. Geophys. Res., 115, D10104, https://doi.org/10.1029/2009JD013035.

Svoboda, M., and Coauthors, 2002: The Drought Monitor. Bull. Amer. Meteor. Soc., 83, 1181-1190, https://doi.org/10.1175/ 1520-0477-83.8.1181.

Tallaksen, L. M., H. Madsen, and B. Clausen, 1997: On the definition and modelling of streamflow drought duration and deficit volume. Hydrol. Sci. J., 42, 15-33, https://doi.org/ 10.1080/02626669709492003.

Tang, Q., S. Peterson, R. H. Cuenca, Y. Hagimoto, and D. P. Lettenmaier, 2009: Satellite-based near-real-time estimation of irrigated crop water consumption. J. Geophys. Res., 114, D05114, https://doi.org/10.1029/2008JD010854.

Tangdamrongsub, N., S. C. Steele-Dunne, B. C. Gunter, P. G. Ditmar, and A. H. Weerts, 2015: Data assimilation of GRACE terrestrial water storage estimates into a regional hydrological model of the Rhine River basin. Hydrol. Earth Syst. Sci., 19, 2079-2100, https://doi.org/10.5194/hess-19-2079-2015.

Thomas, A., J. Reager, J. Famiglietti, and M. Rodell, 2014: A GRACE-based water storage deficit approach for hydrological drought characterization. Geophys. Res. Lett., 41, 15371545, https://doi.org/10.1002/2014GL059323.

Ticconi, F., C. Anderson, J. Figa-Saldaña, J. J. W. Wilson, and H. Bauch, 2017: Analysis of radio frequency interference in Metop ASCAT backscatter measurements. IEEE J. Sel. Top. Appl. Earth Obs. Remote Sens., 10, 2360-2371, https://doi.org/ 10.1109/JSTARS.2016.2640561.

Trenberth, K. E., T. Koike, and K. Onogi, 2008: Progress and prospects for reanalysis for weather and climate. Eos, Trans. Amer. Geophys. Union, 89, 234-235, https://doi.org/10.1029/ 2008EO260002.

Uppala, S. M., and Coauthors, 2005: The ERA-40 Re-Analysis. Quart. J. Roy. Meteor. Soc., 131, 2961-3012, https://doi.org/ 10.1256/qj.04.176.

Xia, Y., and Coauthors, 2012a: Continental-scale water and energy flux analysis and validation for the North American Land Data Assimilation System project phase 2 (NLDAS-2): 1. Intercomparison and application of model products. J. Geophys. Res., 117, D03109, https://doi.org/10.1029/2011JD016048. , and Coauthors, 2012b: Continental-scale water and energy flux analysis and validation for North American Land Data Assimilation System project phase 2 (NLDAS-2): 2. Validation of model-simulated streamflow. J. Geophys. Res., 117, D03110, https://doi.org/10.1029/2011JD016051.

, M. Ek, D. Mocko, C. Peters-Lidard, J. Sheffield, J. Dong, and E. Wood, 2014: Uncertainties, correlations, and optimal blends of drought indices from the NLDAS multiple land surface model ensemble. J. Hydrometeor., 15, 1636-1650, https://doi.org/10.1175/JHM-D-13-058.1.

Xu, X., B. A. Tolson, J. Li, and B. Davison, 2017: Comparison of Xband and L-band soil moisture retrievals for land data assimilation. IEEE J. Sel. Top. Appl. Earth Obs. Remote Sens., 10, 3850-3860, https://doi.org/10.1109/JSTARS.2017.2703988.

Zaitchik, B. F., and M. Rodell, 2009: Forward-looking assimilation of MODIS-derived snow-covered area into a land surface model. J. Hydrometeor., 10, 130-148, https://doi.org/10.1175/ 2008JHM1042.1.

Zhang, Y.-F., T. J. Hoar, Z.-L. Yang, J. L. Anderson, A. M. Toure, and M. Rodell, 2014: Assimilation of MODIS snow cover through the Data Assimilation Research Testbed and the Community Land Model version 4. J. Geophys. Res. Atmos., 119, 7091-7103, https://doi.org/10.1002/2013JD021329. 